\title{
TU/e EmonONEN

\section{The effect of frictional pressure, geometry and wall friction on the modelling of a pseudo-2D bubbling fluidized bed reactor}

\section{Citation for published version (APA):}

Cloete, S., Johansen, S. T., Zaabout, A., Sint Annaland, van, M., Gallucci, F., \& Amini, S. (2015). The effect of frictional pressure, geometry and wall friction on the modelling of a pseudo-2D bubbling fluidized bed reactor.

Powder Technology, 283, 85-102. https://doi.org/10.1016/j.powtec.2015.04.060

\section{Document license: \\ TAVERNE}

DOI:

10.1016/j.powtec.2015.04.060

Document status and date:

Published: 01/01/2015

\section{Document Version:}

Publisher's PDF, also known as Version of Record (includes final page, issue and volume numbers)

\section{Please check the document version of this publication:}

- A submitted manuscript is the version of the article upon submission and before peer-review. There can be important differences between the submitted version and the official published version of record. People interested in the research are advised to contact the author for the final version of the publication, or visit the $\mathrm{DOI}$ to the publisher's website.

- The final author version and the galley proof are versions of the publication after peer review.

- The final published version features the final layout of the paper including the volume, issue and page numbers.

Link to publication

\section{General rights}

Copyright and moral rights for the publications made accessible in the public portal are retained by the authors and/or other copyright owners and it is a condition of accessing publications that users recognise and abide by the legal requirements associated with these rights.

- Users may download and print one copy of any publication from the public portal for the purpose of private study or research.

- You may not further distribute the material or use it for any profit-making activity or commercial gain

- You may freely distribute the URL identifying the publication in the public portal.

If the publication is distributed under the terms of Article 25fa of the Dutch Copyright Act, indicated by the "Taverne" license above, please follow below link for the End User Agreement:

www.tue.nl/taverne

Take down policy

If you believe that this document breaches copyright please contact us at:

openaccess@tue.nl

providing details and we will investigate your claim. 


\title{
The effect of frictional pressure, geometry and wall friction on the modelling of a pseudo-2D bubbling fluidised bed reactor
}

\author{
Schalk Cloete $^{\mathrm{a}}$, Stein Tore Johansen ${ }^{\mathrm{b}}$, Abdelghafour Zaabout ${ }^{\mathrm{b}}$, Martin van Sint Annaland ${ }^{\mathrm{c}}$, \\ Fausto Gallucci ${ }^{\mathrm{c}}$, Shahriar Amini ${ }^{\mathrm{b}, *}$ \\ a Norwegian University of Science and Technology (NTNU), Norway \\ ${ }^{\mathrm{b}}$ Flow Technology Department, SINTEF Materials and Chemistry, Norway \\ c Chemical Process Intensification, Department of Chemical Engineering and Chemistry, Eindhoven University of Technology (TU/e), The Netherlands
}

\section{A R T I C L E I N F O}

\section{Article history:}

Received 25 September 2014

Received in revised form 30 March 2015

Accepted 27 April 2015

Available online 7 May 2015

\section{Keywords:}

Kinetic theory of granular flows

Two fluid model

Fluidised bed reactor

Frictional pressure

Wall friction

\begin{abstract}
A B S T R A C T
The two fluid model (TFM) closed by the kinetic theory of granular flows (KTGF) has been developed to a high level of maturity over the past three decades. However, significant uncertainties still remain about the influence of various closure models on the predictions of the hydrodynamics and especially the reactive performance of fluidised bed reactors. The three factors investigated in this study - frictional pressure, geometry (2D/3D) and friction at the walls - all have significant influences on model predictions of the behaviour of a pseudo-2D bubbling fluidised bed reactor. This study aims to quantify the influence of these important factors on simulation output both in terms of hydrodynamics and reactive performance. Simulations designed to evaluate the effects of these factors were carried out over a wide range of fluidisation velocities, bed loadings and particle sizes to reveal significant impacts on the results. Differences in simulation results varied significantly with changes in the three operating variables investigated (fluidisation velocity, bed loading and particle size) and were analysed in detail. Finally, 3D simulations with wall friction and frictional pressure included showed qualitatively very similar hydrodynamic behaviour to that observed in the experiments. Quantitatively, measurements of the bed expansion ratio compared well for different fluidisation velocities and the particle sizes, but some unexplained differences were still observed in response to changes in the bed loading.
\end{abstract}

(C) 2015 Published by Elsevier B.V.

\section{List of symbols}

Main symbol definitions

$\alpha \quad$ volume fraction

$\phi \quad$ kinetic energy transfer rate $\left(\mathrm{W} / \mathrm{m}^{3}\right)$

$\varphi \quad$ angle of internal friction (degrees)

$\gamma \quad$ dissipation rate $\left(\mathrm{W} / \mathrm{m}^{3}\right)$

$\lambda \quad$ bulk viscosity (Pa s)

$\mu \quad$ viscosity (Pa s)

$\Theta_{\mathrm{s}} \quad$ granular temperature $\left(\mathrm{m}^{2} / \mathrm{s}^{2}\right)$

$\rho \quad$ density $\left(\mathrm{kg} / \mathrm{m}^{2}\right)$

$\varsigma \quad$ specularity coefficient

$\tau_{s} \quad$ particle relaxation time $(\mathrm{s})$

$\overline{\bar{\tau}} \quad$ stress tensor $(\mathrm{Pa})$

$\vec{\tau}_{S} \quad$ particle shear force at the wall (N)

* Corresponding author at: Department of Process Technology, SINTEF Materials and Chemistry, Richard Birkelands Vei 3, 7034 Trondheim, Norway. Tel.: + 4746639721.

E-mail address: shahriar.amini@sintef.no (S. Amini).

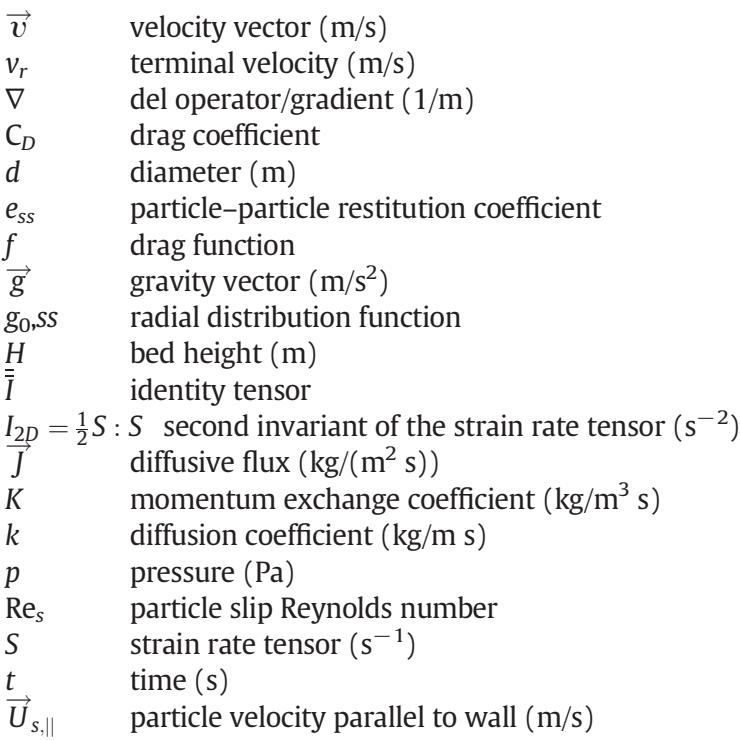


Sub- and superscript definitions

$0 \quad$ initial/static

$\Theta_{s} \quad$ granular temperature

col collisional

exp experiment

fric frictional

g gas or grain

gs inter-phase

kin kinetic

max maximum packing

$s \quad$ solids

sim simulation

$\begin{array}{ll}\text { Abbreviations } \\ \text { ANOVA } & \text { analysis of variance } \\ \text { BER } & \text { bed expansion ratio } \\ \text { by } & \text { interaction effect } \\ \text { CCD } & \text { central composite design } \\ \text { dp } & \text { particle diameter } \\ \text { H0 } & \text { initial static bed height } \\ \text { KTGF } & \text { kinetic theory of granular flows } \\ \text { L } & \text { linear effect } \\ \text { PS } & \text { phase segregation } \\ \text { Q } & \text { quadratic effect } \\ \text { SS } & \text { sum of squares } \\ \text { TFM } & \text { two fluid model } \\ \text { U0 } & \text { fluidisation velocity } \\ \text { X } & \text { reactor performance }\end{array}$

\section{Introduction}

The two fluid model (TFM) closed by the kinetic theory of granular flows (KTGF) [1-3] has been developed to a high level of maturity over the past three decades. For this reason, recent research work involving the TFM for the modelling of fluidised beds has been focusing primarily on specific process applications under the implicit assumption that the underlying models are sufficiently accurate. In terms of model development, the majority of recent research activity has been focused on large scale simulations through a filtered approach (e.g. [4]), but room for improvement still exists in the smaller scale resolved simulations on which these filtered models are based, especially in reactive flows (e.g. [5]).

Pseudo-2D domains are especially useful when it comes to assessing resolved TFM simulations. These domains allow for easy access to local experimental data which can be used to thoroughly evaluate the accuracy of small scale simulations. For example, it has recently been found that the friction on the large front and back walls of a pseudo2D fluidised bed has a very large influence on the solids velocity observed in the unit. When simulating a pseudo-2D unit on a 2D plane using the standard TFM, it was found that the mean solids velocities occurring inside the reactor can be over-predicted by a factor of four [6]. This very large discrepancy was attributed to the neglected friction between the particles and the large front and back walls in the 2D simulation and this will be further studied in this work over a range of fluidisation velocities, particle sizes and bed loadings.

Although the aforementioned study found that the transition from a 2D to a 3D simulation domain had no influence on the solids velocity profiles in itself, this conclusion might not be generally valid. In order to facilitate measurements of the particle velocity using particle image velocimetry combined with digital image analysis (PIV/DIA), relatively large particles $(500 \mu \mathrm{m})$ have been used. These large particles formed large flow structures which maintained distinctly 2D behaviour in the thin bed. Smaller particle sizes, on the other hand, will form smaller particle structures which could be smaller than the thickness of the bed, thereby possibly creating an influence related to the choice between a
2D and 3D simulation geometry. This effect will also be further studied in this work.

In addition, another potential source of error, the influence of the frictional pressure, will be investigated in this work. The majority of published literature on the subject simply uses granular pressure models derived for the kinetic and collisional regimes also in the frictional regime. This is not technically correct because the normal stresses resulting from prolonged contact at very high solids packing are very different in nature compared to the short lived collisions and the subscale translations in the collisional and kinetic regimes. A limited number of papers [7-9] have looked at this effect and found a moderate impact of the frictional pressure on the bubble dynamics and bed expansion. This paper will therefore further evaluate this factor over a wider range of flow conditions.

2D planar simulations without the inclusion of frictional pressure have been compared to pseudo-2D experiments before. One of the most cited studies about the validation of the 2D TFM approach in a bubbling fluidised bed [10] used a pseudo-2D experimental setup and found good comparisons with regard to bed expansion ratio and local solids volume fraction profiles measured with an optical probe. In our previous study [6], bed expansion ratios over a range of fluidisation velocities were evaluated and it was confirmed that the simulated bed expansion ratios mirrored experimental observations almost exactly.

Simulation predictions of the bed expansion under different bed loadings and particle sizes were less accurate, but despite the very large discrepancy in the particle velocity, the predictions of the bed expansion ratio were still acceptable. It therefore appears that the macroscopic hydrodynamic behaviour is not very sensitive to the correct prediction of the solids velocity.

The ultimate aim of such models, however, is to accurately simulate a fluidised bed reactor. Therefore, this study will also include reaction kinetics to investigate the effect of the inclusion of wall friction and frictional pressure not only on the bed hydrodynamics, but also on reactor performance (the degree of conversion achieved). The results will serve as a guideline for subsequent simulation comparisons to reactive experiments performed in a pseudo-2D bubbling fluidised bed reactor.

The decision to limit the scope of this work to the detailed investigation of only three factors (frictional pressure, geometry (2D/3D) and friction at the walls) was based on extensive efforts to improve the match with quantitative and qualitative experimental results reported in Sections 4.1.5 and 4.2 of this work. All three selected factors influence the frictional momentum transfer in the pseudo-2D domain which, due to the large wall/volume ratio, is particularly sensitive to frictional forces exerted by the walls. Other closure models also have an influence on the solution, but the most important of these, the drag law and the particle-particle restitution coefficient in particular, have been explored in quite some detail in the literature to date (e.g. [10-14]). This work will therefore include only a brief assessment of these and other potentially important factors.

\section{Simulations}

\subsection{Model equations}

Conservation equations are solved for each of the two phases present. The continuity equations for the gas and solids phases are given below:

$\frac{\partial}{\partial t}\left(\alpha_{g} \rho_{g}\right)+\nabla \cdot\left(\alpha_{g} \rho_{g} \vec{v}_{g}\right)=0$

$\frac{\partial}{\partial t}\left(\alpha_{s} \rho_{s}\right)+\nabla \cdot\left(\alpha_{s} \rho_{s} \vec{v}_{s}\right)=0$ 
Momentum conservation for the gas phase is written as

$$
\begin{aligned}
\frac{\partial}{\partial t}\left(\alpha_{g} \rho_{g} \vec{v}_{g}\right)+\nabla \cdot\left(\alpha_{g} \rho_{g} \vec{v}_{g} \vec{v}_{g}\right)= & -\alpha_{g} \nabla p+\nabla \cdot \overline{\bar{\tau}}_{g}+\alpha_{g} \rho_{g} \vec{g} \\
& +K_{s g}\left(\vec{v}_{s}-\vec{v}_{g}\right) .
\end{aligned}
$$

And for the solids as

$$
\begin{aligned}
\frac{\partial}{\partial t}\left(\alpha_{s} \rho_{s} \vec{v}_{s}\right)+\nabla \cdot\left(\alpha_{s} \rho_{s} \vec{v}_{s} \vec{v}_{s}\right)= & -\alpha_{s} \nabla p-\nabla p_{s}+\nabla \cdot \overline{\bar{\tau}}_{s}+\alpha_{s} \rho_{s} \vec{g} \\
& +K_{g s}\left(\vec{v}_{g}-\vec{v}_{s}\right) .
\end{aligned}
$$

The inter-phase momentum exchange coefficient $\left(K_{g s}=K_{s g}\right)$ was modelled according to the formulation of Syamlal and O'Brien [3]. This formulation makes the implicit assumption that the influence of the fluctuating velocity component on the drag interaction is negligibly small, an assumption which should be valid in the dense beds investigated in this study.

$$
\begin{aligned}
& K_{g s}=K_{s g}=\frac{\alpha_{s} \rho_{s} f}{\tau_{s}} \\
& f=\frac{\mathrm{C}_{D} \operatorname{Re}_{s} \alpha_{g}}{24 v_{r, s}^{2}} \\
& C_{D}=\left(0.63+\frac{4.8}{\sqrt{\operatorname{Re}_{s} / v_{r, s}}}\right)^{2} \\
& v_{r, s}=0.5\left(A-0.06 \operatorname{Re}_{s}+\sqrt{\left(0.06 \operatorname{Re}_{s}\right)^{2}+0.12 \operatorname{Re}_{s}(2 B-A)+A^{2}}\right) \\
& A=\alpha_{g}^{4.14} \\
& B=0.8 \alpha_{g}^{1.28} \quad \alpha_{g} \leq 0.85 \\
& B=\alpha_{g}^{2.65} \quad \alpha_{g}>0.85 \\
& \operatorname{Re}_{s}=\frac{\rho_{g} d_{s}\left|\vec{v}_{s}-\vec{v}_{g}\right|}{\mu_{g}} \\
& \tau_{s}=\frac{\rho_{s} d_{s}^{2}}{18 \mu_{g}}
\end{aligned}
$$

Species mass balances for the gas phase read:

$\frac{\partial}{\partial t}\left(\alpha_{g} \rho_{g} Y_{g i}\right)+\nabla \cdot\left(\alpha_{g} \rho_{g} \vec{v}_{g} Y_{g i}\right)=\nabla \cdot \alpha_{g} \vec{J}_{g i}+\alpha_{g} S_{g i}$.

It should be noted that no turbulent dispersion of gas species was included based on previous work which found this effect to be very small [5]. Furthermore, no energy conservation was included under the assumption of isothermal flow. This is usually a good assumption due to the excellent mixing achieved in fluidised bed reactors.

Solids phase stresses were described according to the KTGF theory where the random particle motion is modelled in analogy with the thermal motion of molecules in a gas using the concept of the granular temperature. The conservation equation for granular temperature is given below:

$\frac{3}{2}\left[\frac{\partial}{\partial t}\left(\alpha_{s} \rho_{s} \Theta_{s}\right)+\nabla \cdot\left(\alpha_{s} \rho_{s} \vec{v}_{s} \Theta_{s}\right)\right]=\left(-p_{s} \overline{\bar{I}}+\overline{\bar{\tau}}_{s}\right): \nabla \vec{v}_{s}+\nabla \cdot\left(k_{\theta_{s}} \nabla \Theta_{s}\right)-\gamma_{\theta_{s}}+\phi_{g s}$.

This partial differential equation was simplified to an algebraic equation by neglecting the convection and diffusion terms - an often used assumption in dense, slow moving fluidised beds where the local generation and dissipation of granular temperature far outweigh the transport by convection and diffusion [15]. The two final terms in Eq. (14) are the collisional dissipation of energy [1] and the interphase exchange between the particle fluctuations and the gas phase [2]:

$\gamma_{\Theta_{s}}=\frac{12\left(1-e_{s s}^{2}\right) g_{0, s s}}{d_{s} \sqrt{\pi}} \rho_{s} \alpha_{s}^{2} \Theta_{s}^{3 / 2}$

$\phi_{g s}=-3 K_{g s} \Theta_{s}$.

Solids stresses in Eq. (17) are calculated according to shear and bulk [1] viscosities due to particle momentum exchange through translation and collision.

$\overline{\bar{\tau}}_{s}=\alpha_{s} \mu_{s}\left(\nabla \overrightarrow{\boldsymbol{v}}_{s}+\nabla \overrightarrow{\boldsymbol{v}}_{s}^{T}\right)+\alpha_{s}\left(\lambda_{s}-\frac{2}{3} \mu_{s}\right) \nabla \cdot \overrightarrow{\boldsymbol{v}}_{s} \overline{\bar{I}}$

$\lambda_{s}=\frac{4}{3} \alpha_{s} \rho_{s} d_{s} g_{0, s s}\left(1+e_{s S}\right)\left(\frac{\Theta_{s}}{\pi}\right)^{1 / 2}$

The shear viscosity $\left(\mu_{s}\right)$ consists of three parts: collisional [2,3], kinetic [3] and frictional [16]:

$\mu_{s, c o l}=\frac{4}{5} \alpha_{s} \rho_{s} d_{s} g_{0, s s}\left(1+e_{s s}\right)\left(\frac{\Theta_{s}}{\pi}\right)^{1 / 2}$

$\mu_{s, k i n}=\frac{10 \rho_{s} d_{s} \sqrt{\Theta_{s} \pi}}{96\left(1+e_{s s}\right) g_{0, s s}}\left[1+\frac{4}{5} \alpha_{s} g_{0, s s}\left(1+e_{s s}\right)\right]^{2}$

$\mu_{s . f r i c}=\frac{p_{s} \sin \varphi}{\sqrt{I_{2 D}}}$.

Granular temperature as well as the radial distribution function (measure of the average distance between particles) is used to determine the solids pressure ( $p_{s}$ in Eq. (4)). The solids pressure formulation by Lun et al. [1] was complemented by the radial distribution function of Ogawa and Oshima [17]:

$p_{s}=\alpha_{s} \rho_{s} \Theta_{s}+2 \rho_{s}\left(1-e_{s s}\right) \alpha_{s}^{2} g_{0, s s} \Theta_{s}$

$g_{0, s s}=\left[1-\left(\frac{\alpha_{s}}{\alpha_{s, \max }}\right)^{1 / 3}\right]^{-1}$.

The influence of the frictional pressure formulation on the reactor performance was also evaluated in this work. The majority of simulation studies in the literature have simply assumed that the solids pressure derived by Lun et al. [1] holds in the frictional regime as well and used this frictional pressure to calculate the frictional component of the shear viscosity [16].

However, this is not technically correct because the normal stresses in the frictional regime are very different in nature from the normal stresses in the kinetic and collisional regimes for which Eq. (22) was derived. The most popular model for frictional pressure available in the open literature [18] will therefore be implemented in this study to investigate its effect:

$p_{s, f r i c}=\operatorname{Fr} \frac{\left(\alpha_{s}-\alpha_{s, \min }\right)^{n}}{\left(\alpha_{s, \max }-\alpha_{s}\right)^{p}}$.

$F r=0.1 \alpha_{s}, n=2$ and $p=5$ are empirical constants and $\alpha_{s, \min }=0.5$ is the volume fraction limit above which Eq. (24) is activated and added to the solids pressure calculated in Eq. (22). The solids pressure returned by Eq. (24) can be orders of magnitude larger than that of Eq. (22) and has the effect of keeping the emulsion phase volume fraction significantly below maximum packing. 
Reaction kinetics was implemented in the form of a simple catalytic conversion of gas species A to gas species $\mathrm{B}$.

$\mathrm{A}+\mathrm{S} \rightarrow \mathrm{B}+\mathrm{S}$

The physical properties of species A and B were specified to be identical so that the reaction would not influence the hydrodynamics resulting in a non-linear interaction. This will significantly simplify the interpretation of the results, enabling clearly decoupled conclusions regarding hydrodynamic and reaction kinetic bed behaviour to be drawn from each simulation.

Since all parameters investigated in this study only influence the hydrodynamics of the reactor, this reaction setup allowed for a direct assessment of how changes in hydrodynamic behaviour influence the reactive performance of the bed. Direct reaction rate effects such as different kinetic rates at different temperatures and interactions between multiple reactions are outside the scope of this work. In addition, this reaction setup allowed for hydrodynamic comparisons to cold flow experiments even while the effect of different simulation parameters on reaction kinetic performance was evaluated according to the hypothetical room temperature catalytic reaction described above.

A simple hypothetical reaction rate expression was implemented under the assumption that the first order catalytic reaction takes place throughout the particle:

$R^{H}=5 \alpha_{s} x_{A}$

The reaction rate in each cell (molar rate of change from species A to species B per unit volume) was then implemented as a source term into Eq. (13). Since the species had identical properties and the reaction occurred in a 1:1 stoichiometric ratio, no mass or momentum source terms were required. The source term in Eq. (13) was taken as $S_{g i}=$ $R^{H} M_{i}$ for the product species (B) and $S_{g i}=R^{H} M_{i}$ for the reactant species (A).

\subsection{Boundary conditions}

A simple no-slip wall boundary condition was set for the gas phase. The Johnson and Jackson [18] boundary condition was used for the granular phase with a specularity coefficient of 0.5 .

$\vec{\tau}_{s}=-\frac{\pi}{6} \sqrt{3} \varsigma \frac{\alpha_{s}}{\alpha_{s, \max }} \rho_{s} g_{0, s s} \sqrt{\Theta_{s}} \vec{U}_{s, \|}$

The inlet condition was specified as a velocity inlet according to the specific simulation run in question and the outlet was designated as a pressure outlet at atmospheric pressure.

\subsection{Flow solver and solver settings}

The commercial software package, ANSYS FLUENT 13.0, was used as the flow solver. The phase coupled SIMPLE scheme [19] was used for pressure-velocity coupling and the higher order QUICK scheme [20] for the spatial discretisation of the convective fluxes. First order implicit temporal discretisation was used.

A special issue to notice is the numerical treatment of disappearing phases. This is handled inside the code without a possibility for user intervention. Hence, it should be noted that uncertainty exists about the solution of the transport equations in the limit of a disappearing solids phase. Analysis of simulation outputs suggests that the FLUENT solver sets values of velocity (Eq. (4)) and granular temperature (Eq. (14)) to low constant values in this limit. This treatment is critical for the code to compute when the solids fraction disappears. However, we have no evidence that this treatment significantly impacts the simulation results.

\subsection{Geometry and meshing}

Two geometries were evaluated in this work: a 2D plane and a full $3 \mathrm{D}$ domain of the pseudo-2D experimental unit. Both geometries had the dimensions of the experimental unit. The plane was $0.3 \mathrm{~m}$ in width and $1.5 \mathrm{~m}$ in height, while the 3D geometry also included the $0.015 \mathrm{~m}$ bed thickness.

Meshing was done using a simple structured grid of completely square/cubic cells. The smallest affordable grid size of $2.5 \mathrm{~mm}$ was used in a uniform structured mesh. As was previously shown by the authors [6], this grid size is sufficiently fine for all but the finest particle sizes considered in this study. It should be considered, however, that limited grid dependency effects (e.g. a slight over-expansion of the bed) can be expected for the cases using $150 \mu \mathrm{m}$ particles in Table 2 .

The top $10 \%$ of the geometry was specified as a porous zone with the purpose of attaining a plug flow of gas through the outlet. If this is not done, backflows regularly occur over the outlet. Since the species mass fraction of these backflows needs to be specified, it is a potential source of error when measuring the conversion attained in the reactor. These backflows were therefore avoided by including the porous zone. It was explicitly confirmed that the inclusion of this porous zone had no influence on the transport phenomena in the solids bed.

\subsection{Initial conditions}

The solution was initialised with zero velocity and solids material at a volume fraction of 0.6 up to the initial static bed height used in each specific experiment. The solution was run for $5 \mathrm{~s}$ in order to attain a quasi-steady flow condition. This solution was then used as the initial condition for time-averaging.

\subsection{Simulation summary}

A summary of the physical properties and simulation parameters is given in Table 1.

\section{Data collection and processing}

Three performance measures (dependent variables) were evaluated by changing three factors (independent variables) in a designed experiment. All performance measures were calculated from time averaged data collected over a time period sufficiently long for the fluidising gas to pass through the reactor 20 times. An example of the evolution of the time-averaged performance measures described in the next section is given in Fig. 1 to illustrate the adequacy of this averaging period.

\subsection{Performance measures}

\subsubsection{Reactor performance}

This is the primary performance measure of interest in fluidised bed reactors and is calculated as follows from the average mass fraction

Table 1

Physical properties and simulation parameters.

\begin{tabular}{ll}
\hline Gas density & $1.225 \mathrm{~kg} / \mathrm{m}^{3}$ \\
Gas viscosity & $1.789 \times 10^{-5} \mathrm{~kg} / \mathrm{m} \mathrm{s}$ \\
Particle density & $2500 \mathrm{~kg} / \mathrm{m}^{3}$ \\
Particle sizes & $90,150,250,350 \& 500 \mu \mathrm{m}$ \\
Bed dimensions & $1.5 \mathrm{~m} \times 0.3 \mathrm{~m} \times 0.015 \mathrm{~m}$ \\
Particle-particle restitution & 0.9 \\
Specularity coefficient & 0.5 \\
Angle of internal friction & $30^{\circ}$ \\
Friction packing limit & 0.5 \\
Maximum packaging limit & 0.63 \\
\hline
\end{tabular}




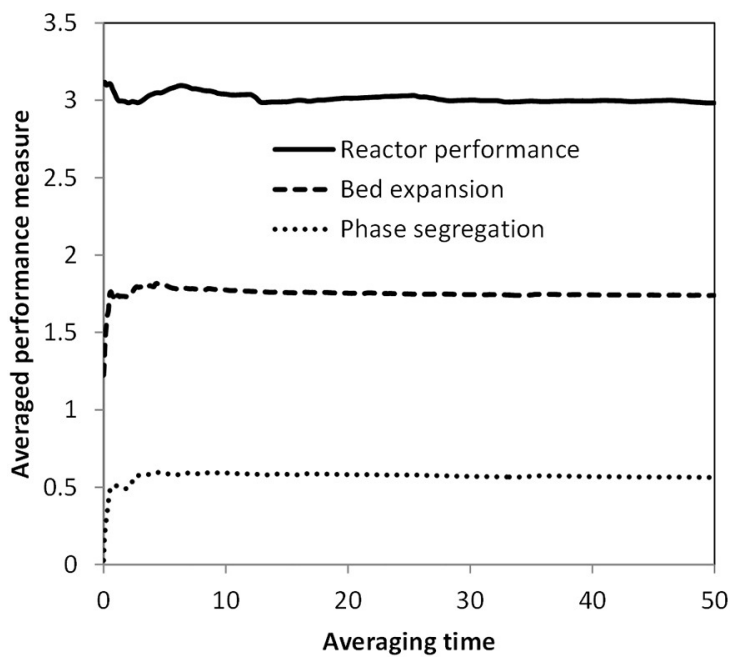

Fig. 1. The evolution of the time-averaged reactor performance, bed expansion ratio and phase segregation along the averaging period.

$\left(x_{A, \text { outlet }}\right)$ of reactant $(\mathrm{A})$ exiting the reactor unreacted (averaged in time and space over the reactor outlet):

$X=-\log \left(x_{A, \text { outlet }}\right)$.

This measure can be interpreted as a measure of the residence time required to convert the reactant to a certain degree when all other factors influencing reaction rate are kept constant. In this case, for a first order reaction, the rate of change of the reacting species mass fraction would be expressed as follows: $d x / d t=-C x$ which can be integrated from $x_{0}=1$ at $t_{0}=0$ to find the time $(t)$ at a certain final conversion $(x)$ as $t=-C^{-1} \ln (x)$. In this case it was assumed that the constant $C^{-1}=\log (e)$ in order to express time $(t)$ required to reach a given conversion $(x)$ as $t=-\log (x)$. This measure was used as the primary indicator of reactor performance (Eq. (27)).

The base 10 logarithm was chosen simply to make the results easier to interpret. For instance, $0 \%$ conversion would return a reactor performance of $-\log (1)=0,90 \%$ conversion would return a reactor performance of $-\log (0.1)=1,99 \%$ conversion a reactor performance of $-\log (0.01)=2$ etc. In practice, this measure linearises reactor performance achieved from a first order reaction and makes it possible to better distinguish between cases which achieve high conversions.

\subsubsection{Bed expansion ratio}

The bed expansion ratio is the expanded bed height divided by the initial static bed height. The expanded bed height was calculated as the height at which the solids volume fraction (averaged in time and cross-stream space) is 0.05 . Below this line, the dense bed region exists at much higher solids volume fractions and above this line, the freeboard region exists at volume fractions close to zero. This measure was therefore found to be a good indicator of the expanded bed height. From a reactor performance point of view, this performance measure indicates the average residence time of the gas inside the bed. A more compact bed (lower bed expansion ratio) has a doubly reductive influence on gas residence time by shortening the distance that the gas can travel inside the bed and by increasing the actual gas velocity due to a decrease in gas voidage.

\subsubsection{Phase segregation}

This performance measure was quantified as the volume average of the RMS (root mean square) of the solids volume fraction over the bed divided by the initial static bed height. A high value of this performance measure indicates large volume fraction fluctuations during the averaging process and therefore significant solids volume fraction heterogeneities. From a reactor performance point of view, this performance measure indicates the quality of gas-solid contacting achieved in the reactor. A high degree of phase segregation implies reduced contacting between the solids and the gas and thereby reduced reactor performance.

\subsection{Independent variables}

Experiments and simulations were carried out based on a three factor central composite design [21]. This is a form of experimental design where the response of specific dependent variables (performance measures discussed in the previous section) to changes in various independent variables can be easily assessed, accurately quantified and visualised. The three independent variables, henceforth called factors, considered in the design were specified over five levels as follows:

- Gas flow rate $(\mathrm{U})$. This factor was evaluated at gas injection velocities of $0.264,0.4,0.6,0.8$ and $0.936 \mathrm{~m} / \mathrm{s}$. These velocities produced fluidisation falling in the bubbling fluidisation regime for all the runs in the central composite design.

- Static bed height $(\mathrm{H})$. The initial packed bed height was evaluated at five levels: $0.132,0.2,0.3,0.4$ and $0.468 \mathrm{~m}$. These measures ensured significant variations in the expanded bed height, but kept the bed material from over-expanding out of the experimental unit.

- Particle diameter (d). Five narrow particle size ranges were used: 70$110,100-200,200-300,300-400$ and 400-600 $\mu \mathrm{m}$. Ideally, the particle sizes would have averages of: $82,150,250,350$ and $418 \mu \mathrm{m}$ to maintain rotatability of the design. Rotatability is the characteristic that all experimental points are located at the same normalised distance from the centrepoint of the design $(U=0.6 \mathrm{~m} / \mathrm{s}, \mathrm{H}=0.3 \mathrm{~m}$ and $\mathrm{d}=250 \mu \mathrm{m}$ ) and is a desirable property for optimisation studies. In this case, however, an optimal point is not expected within the parameter space, but rather a steady increase or decrease (e.g. it is expected that the bed expansion continues to increase with a decrease in the particle size). Accuracy will therefore not be significantly affected by the partial rotatability of this design.

\subsection{Data analysis}

The central composite design was run for the experiments and the simulations, requiring 16 runs in each case (Table 2 ). This facilitated a direct and easily quantifiable comparison between different model setups and also between model and experimental results. The main

\section{Table 2}

Case specification for the 16 runs in the central composite design completed both for the experiments and the simulations together with the simulated and experimental bed expansion ratios. The central point in the design (C) is normally repeated (cases 15 and 16 ) in order to better judge the amount of unexplained variance in the data.

\begin{tabular}{llll}
\hline Case number & $\begin{array}{l}\text { Fluidisation velocity } \\
(\mathrm{m} / \mathrm{s})\end{array}$ & $\begin{array}{l}\text { Static bed height } \\
(\mathrm{m})\end{array}$ & $\begin{array}{l}\text { Particle size } \\
(\mu \mathrm{m})\end{array}$ \\
\hline 1 & 0.4 & 0.2 & 150 \\
2 & 0.4 & 0.2 & 350 \\
3 & 0.4 & 0.4 & 150 \\
4 & 0.4 & 0.4 & 350 \\
5 & 0.8 & 0.2 & 150 \\
6 & 0.8 & 0.2 & 350 \\
7 & 0.8 & 0.4 & 150 \\
8 & 0.8 & 0.4 & 350 \\
9 & 0.264 & 0.3 & 250 \\
10 & 0.936 & 0.3 & 250 \\
11 & 0.6 & 0.132 & 250 \\
12 & 0.6 & 0.468 & 250 \\
13 & 0.6 & 0.3 & 90 \\
14 & 0.6 & 0.3 & 500 \\
$15(\mathrm{C})$ & 0.6 & 0.3 & 250 \\
$16(\mathrm{C})$ & 0.6 & 0.3 & 250 \\
\hline
\end{tabular}


section of this paper will mostly focus on quantifying the differences between different model setups.

Results will primarily be displayed in two ways: an analysis of variance (ANOVA) and response surfaces of dependent variables to changes in various factors (independent variables). The ANOVA will be used to clearly identify the most significant factors in the design (i.e. those where changes in the model setup significantly affected the way in which the reactor performance responded to changes in the specific factor).

The significance of factors will be defined by the p-value which is an indication of the probability that the observed response was purely random. If this value becomes small $(p<0.05)$, the effect is said to be significant because the probability of it occurring by random chance is sufficiently small. A value of $p<0.01$ is generally regarded as highly significant. The p-value is calculated from the F-test which weighs the amount of explained variance in the design against the amount of unexplained variance (experimental error, rounding error, averaging error, data not fitting the second order model etc.). This ratio can then be evaluated as a p-value to decide whether any observed variance is caused by a significant effect or is simply random.

The relative variance explained by each factor will also be given as the percentage of the total sum of squares (SS). The total sum of squares for a specific dependent variable is the sum of all the squared differences between all the experimental points and the mean. A larger total sum of squares implies that experimental observations are scattered wide around the mean and there is a lot of variance in the design. This measure will give an indication of the importance of significant effects relative to each other.

Once the significant effects are identified in this way, the difference between simulation and experiment will be plotted on a response surface as a function of these highly significant factors in order to gain an understanding of the nature of any significant difference.

In case more details are sought, the interested reader is referred to the aforementioned reference [21] for a more detailed theoretical description of a central composite design.

\section{Results and discussion}

Results will be discussed in three sections: a central composite design to establish how four different simulation setups differ between each other and with experimental results [6] over the parameter space investigated, a discussion on the qualitative differences and similarities between the different simulation setups and experiments, and a brief investigation into the influences of various other potentially influential model settings.
Table 4

ANOVA table summarising the response of the three performance measures extracted from CCD 4 to changes in the three factors investigated. Significant factors are shown in bold, while highly significant factors are shown in bold italics. The factors are denoted by UO (fluidisation velocity), HO (static bed height), and dp (particle diameter). Different effects are indicated by L (linear), Q (quadratic) and by (interaction).

\begin{tabular}{|c|c|c|c|c|c|c|}
\hline \multirow[t]{2}{*}{ Effect } & \multicolumn{2}{|c|}{$\begin{array}{l}\text { Reactor } \\
\text { performance }\end{array}$} & \multicolumn{2}{|c|}{$\begin{array}{l}\text { Bed expansion } \\
\text { ratio }\end{array}$} & \multicolumn{2}{|c|}{ Phase segregation } \\
\hline & SS & p-Value & SS & p-Value & SS & p-Value \\
\hline U0 (L) & 55.80 & 0.0000 & 55.68 & 0.0000 & 66.49 & 0.0000 \\
\hline UO (Q) & 9.13 & 0.0031 & 0.00 & 0.9724 & 2.78 & 0.0204 \\
\hline $\mathrm{HO}(\mathrm{L})$ & 8.16 & 0.0039 & 2.39 & 0.0134 & 0.50 & 0.2136 \\
\hline $\mathrm{HO}(\mathrm{Q})$ & 0.04 & 0.7297 & 0.25 & 0.2801 & 1.46 & 0.0598 \\
\hline $\mathrm{dp}(\mathrm{L})$ & 14.14 & 0.0012 & 33.17 & 0.0000 & 22.48 & 0.0002 \\
\hline $\mathrm{dp}(\mathrm{Q})$ & 0.15 & 0.5220 & 3.23 & 0.0074 & 0.82 & 0.1295 \\
\hline UO by $\mathrm{HO}$ & 0.75 & 0.1845 & 0.30 & 0.2452 & 0.36 & 0.2821 \\
\hline U0 by dp & 9.87 & 0.0026 & 2.71 & 0.0105 & 0.48 & 0.2247 \\
\hline HO by dp & 0.36 & 0.3395 & 1.41 & 0.0350 & 3.38 & 0.0142 \\
\hline Error & 1.59 & & 0.86 & & 1.24 & \\
\hline Total & 100.00 & & 100.00 & & 100.00 & \\
\hline
\end{tabular}

\subsection{Central composite designs}

Four different central composite designs (CCDs) were completed and compared over the parameter space in question. These were 2D simulations neglecting frictional pressure (CCD 1), 2D simulations including frictional pressure (Eq. (24)) (CCD 2), 3D simulations including frictional pressure, but neglecting wall friction on the front and back walls (CCD 3) and 3D simulations including frictional pressure and wall friction (CCD 4). These four central composite designs will be compared against each other for each of the three performance measures described in Section 3.1 and also against experimental results [6] for the bed expansion ratio.

For each of the performance measures, results will be reported to assess the influence of the frictional pressure (difference between CCDs 1 and 2), the influence of the 3D geometry (difference between CCDs 2 and 3 ) and the influence of the wall friction (difference between CCDs 3 and 4).

\subsubsection{Simulation results}

The results for all the cases are given in Table 3. It is important to note that case 13 (the finest particle size) has been omitted just like it was in the previous study [6]. From a simulation point of view, it was not possible to attain sufficient grid independent solutions for this fine particle class. It is also expected that additional modelling will have to be included to account for adhesion forces that become significant for

Table 3

Simulation results for the four central composite designs completed in this study. Experimental results for the bed expansion ratio are also included.

\begin{tabular}{|c|c|c|c|c|c|c|c|c|c|c|c|c|c|c|c|c|}
\hline \multirow[t]{2}{*}{ Case nr. } & \multirow[t]{2}{*}{$\mathrm{UO}(\mathrm{m} / \mathrm{s})$} & \multirow[t]{2}{*}{$\mathrm{HO}(\mathrm{m})$} & \multirow[t]{2}{*}{$\mathrm{dp}(\mu \mathrm{m})$} & \multicolumn{4}{|c|}{ Reactor performance } & \multicolumn{5}{|c|}{ Bed expansion ratio } & \multicolumn{4}{|c|}{ Phase segregation } \\
\hline & & & & CCD 1 & $\mathrm{CCD} 2$ & CCD 3 & CCD 4 & Exp & CCD 1 & $\mathrm{CCD} 2$ & $\mathrm{CCD} 3$ & $\mathrm{CCD} 4$ & CCD 1 & $\mathrm{CCD} 2$ & $\mathrm{CCD} 3$ & CCD 4 \\
\hline 1 & 0.40 & 0.20 & 150 & 2.35 & 2.50 & 2.24 & 2.71 & 1.95 & 2.01 & 2.07 & 1.79 & 1.86 & 0.81 & 0.75 & 0.66 & 0.59 \\
\hline 2 & 0.40 & 0.20 & 350 & 4.00 & 4.75 & 4.40 & 5.46 & 1.61 & 1.42 & 1.43 & 1.40 & 1.40 & 0.52 & 0.44 & 0.42 & 0.42 \\
\hline 3 & 0.40 & 0.40 & 150 & 3.06 & 2.60 & 2.92 & 3.80 & 1.55 & 1.80 & 1.80 & 1.67 & 1.71 & 0.72 & 0.66 & 0.61 & 0.52 \\
\hline 4 & 0.40 & 0.40 & 350 & 6.10 & 7.03 & 6.30 & 7.39 & 1.37 & 1.34 & 1.36 & 1.38 & 1.35 & 0.46 & 0.40 & 0.37 & 0.42 \\
\hline 5 & 0.80 & 0.20 & 150 & 1.41 & 1.45 & 1.59 & 2.13 & 2.78 & 2.76 & 2.72 & 2.59 & 2.38 & 1.07 & 1.02 & 0.83 & 0.74 \\
\hline 6 & 0.80 & 0.20 & 350 & 1.89 & 2.05 & 1.98 & 2.24 & 2.41 & 1.98 & 2.01 & 1.79 & 1.93 & 0.78 & 0.76 & 0.74 & 0.58 \\
\hline 7 & 0.80 & 0.40 & 150 & 1.86 & 1.52 & 2.07 & 2.69 & 2.05 & 2.41 & 2.35 & 2.26 & 2.15 & 0.96 & 0.91 & 0.79 & 0.67 \\
\hline 8 & 0.80 & 0.40 & 350 & 2.78 & 2.67 & 2.72 & 3.07 & 1.71 & 1.84 & 1.90 & 1.78 & 1.84 & 0.71 & 0.69 & 0.66 & 0.63 \\
\hline 9 & 0.26 & 0.30 & 250 & 6.08 & 6.65 & 6.67 & 7.52 & 1.38 & 1.31 & 1.36 & 1.34 & 1.35 & 0.46 & 0.39 & 0.38 & 0.37 \\
\hline 10 & 0.94 & 0.30 & 250 & 1.76 & 1.66 & 1.91 & 2.22 & 2.32 & 2.13 & 2.16 & 2.12 & 2.20 & 0.91 & 0.90 & 0.78 & 0.62 \\
\hline 11 & 0.60 & 0.13 & 250 & 1.65 & 1.72 & 1.66 & 2.04 & 2.48 & 1.98 & 2.06 & 1.87 & 1.94 & 0.80 & 0.80 & 0.73 & 0.60 \\
\hline 12 & 0.60 & 0.47 & 250 & 3.10 & 2.90 & 2.97 & 3.54 & 1.69 & 1.77 & 1.80 & 1.72 & 1.75 & 0.68 & 0.66 & 0.64 & 0.60 \\
\hline 14 & 0.60 & 0.30 & 500 & 4.28 & 5.00 & 4.72 & 5.41 & 1.64 & 1.46 & 1.45 & 1.44 & 1.44 & 0.53 & 0.44 & 0.43 & 0.46 \\
\hline 15 & 0.60 & 0.30 & 250 & 2.59 & 2.62 & 2.59 & 2.91 & 1.86 & 1.85 & 1.93 & 1.73 & 1.84 & 0.73 & 0.71 & 0.65 & 0.55 \\
\hline 16 & 0.60 & 0.30 & 250 & 2.57 & 2.66 & 2.62 & 2.98 & 1.84 & 1.88 & 1.96 & 1.76 & 1.80 & 0.74 & 0.69 & 0.64 & 0.57 \\
\hline
\end{tabular}



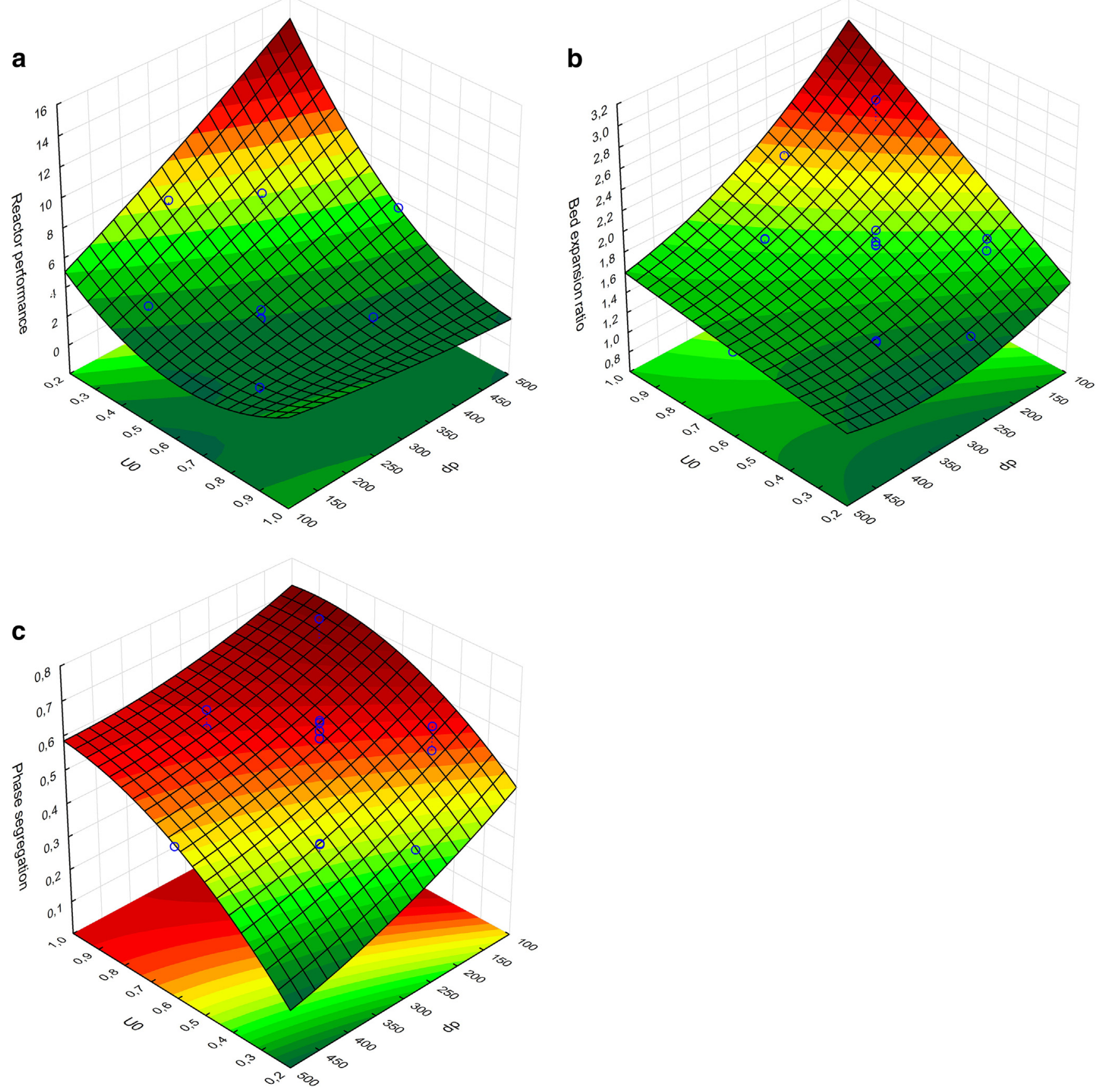

Fig. 2. Response of the three reactor performance measures to changes in the two most influential factors: fluidisation velocity (U0) and particle size (dp).

fine particles. In terms of experiments, the measurements of the bed expansion ratio were also very uncertain for this case because fines were entrained upward, creating the impression of more bed expansion than there actually was. For these reasons, this case was simply removed from the study. This omission will not impact the conclusions of this work.

In order to form an idea about how the reactor behaves, the results for the 3D case with wall friction (CCD 4) in Table 3 will be briefly analysed. The ANOVA results for CCD 4 are given in Table 4 .

It is shown that the effect of the static bed height is the weakest of the three factors investigated. It seems to have no influence on the degree of phase segregation achieved and only a minor influence on the bed expansion ratio. The effect on reactor performance is also smaller than expected considering that a taller bed will increase the gas residence time and therefore achieve more conversion. The response of the three reactor performance measures to changes in the two most influential factors (fluidisation velocity and particle size) is presented in Fig. 2.

It is clear that the reactor performance increases greatly with decreases in fluidisation velocity. This happens because the gas residence time is inversely proportional to the fluidisation velocity and because lower gas flow rates create smaller bubbles and therefore better contact between the gas and the solids. The increase in reactor performance with particle size is due to improved bubble-to-emulsion mass transfer. As discussed in more detail in a previous study [22], this is primarily due to the fact that an emulsion of coarser particles is much more penetrable to gaseous reactants than an emulsion of fine particles.

When looking at the hydrodynamic measures, the effect of fluidisation velocity is quite self-explanatory. Larger fluidisation velocities increase the bed expansion ratio and the phase segregation (because of larger 
and more distinct bubbles). A decrease in particle size has a similar effect to an increase in fluidisation velocity because smaller particles experience a greater drag force from the fluidising gas.

\subsubsection{Influence of frictional pressure}

In order to quantify the influence of the frictional pressure on the simulation results, the deviation of the results from CCD 1 from those of CCD 2 will now be analysed. The deviation will be expressed as a percentage. Taking the reactor performance as an example, the deviation of CCD 1 from CCD 2 would be calculated as follows for each run in the central composite design: $\left(X_{\mathrm{CCD} 1}-X_{\mathrm{CCD} 2}\right) / X_{\mathrm{CCD} 2} \times 100 \%$. A positive value would therefore imply that the result from CCD 1 was greater than the result from CCD 2 and vice versa for a negative value. These deviations were analysed in the central composite design to yield the ANOVA given in Table 5.

In addition to the ANOVA, two additional statistics can be given to aid in the interpretation of the results. These are the mean and the standard deviation of the difference between the data points in CCDs 1 and 2 as given below:

- Reactor performance: $-1.38 \pm 10.66$

- Bed expansion ratio: $-1.58 \pm 1.96$

- Phase segregation: $7.79 \pm 6.28$.

These data indicate that the neglect of the frictional pressure (which is the difference between CCDs 1 and 2) did not make a meaningful difference in the prediction of the bed expansion ratio, but had a greater effect on the reactor performance and phase segregation.

The positive mean deviation in the phase segregation (7.79\%) implies that ignoring the frictional pressure causes greater segregation of the solids phase. This is primarily due to the emulsion phase which is calculated to be very close to the maximum packing limit (0.63) when the frictional pressure is neglected, but significantly lower $(\sim 0.57)$ when the frictional pressure is included.

The significant standard deviation in the percentage by which CCD 1 deviates from CCD 2 (6.28\%) implies that this difference varies significantly with the different factors. Looking at Table 5 , it can be seen that the vast majority of this variance occurs in response to changes in the fluidisation velocity with a small amount of variance also explained by changes in the particle size. The response surface in Fig. 3 clarifies this observation.

It is clear that the difference between the central composite designs is greatest at low fluidisation velocities and large particle sizes. These are the cases when the bed is most compact and the emulsion phase occupies the majority of the bed. In these cases, the aforementioned

\section{Table 5}

ANOVA table summarising the response of the deviations of CCD 1 from CCD 2 to changes in the three factors investigated. Significant factors are shown in bold, while highly significant factors are shown in bold italics. The factors are denoted by UO (fluidisation velocity), $\mathrm{HO}$ (static bed height), and dp (particle diameter). Different effects are indicated by L (linear), Q (quadratic) and by (interaction).

\begin{tabular}{|c|c|c|c|c|c|c|}
\hline \multirow[t]{2}{*}{ Effect } & \multicolumn{2}{|c|}{$\begin{array}{l}\text { Reactor } \\
\text { performance }\end{array}$} & \multicolumn{2}{|c|}{$\begin{array}{l}\text { Bed expansion } \\
\text { ratio }\end{array}$} & \multicolumn{2}{|c|}{ Phase segregation } \\
\hline & SS & p-Value & SS & p-Value & SS & p-Value \\
\hline $\mathrm{U} 0(\mathrm{~L})$ & 15.78 & 0.0115 & 7.64 & 0.0489 & 60.91 & 0.0005 \\
\hline U0 (Q) & 0.07 & 0.8111 & 5.02 & 0.0901 & 4.94 & 0.0758 \\
\hline $\mathrm{HO}(\mathrm{L})$ & 30.97 & 0.0028 & 2.07 & 0.2359 & 0.28 & 0.6204 \\
\hline $\mathrm{HO}(\mathrm{Q})$ & 0.86 & 0.4041 & 4.80 & 0.0954 & 2.09 & 0.2061 \\
\hline $\mathrm{dp}(\mathrm{L})$ & 33.54 & 0.0024 & 15.77 & 0.0137 & 1.83 & 0.2319 \\
\hline $\mathrm{dp}(\mathrm{Q})$ & 1.62 & 0.2667 & 39.13 & 0.0021 & 11.76 & 0.0183 \\
\hline UO by $\mathrm{H} 0$ & 0.83 & 0.4135 & 0.35 & 0.6030 & 0.05 & 0.8318 \\
\hline UO by dp & 2.38 & 0.1906 & 12.36 & 0.0217 & 11.86 & 0.0180 \\
\hline HO by dp & 8.75 & 0.0337 & 7.16 & 0.0541 & 1.35 & 0.2960 \\
\hline Error & 5.20 & & 5.70 & & 4.95 & \\
\hline Total & 100.00 & & 100.00 & & 100.00 & \\
\hline
\end{tabular}

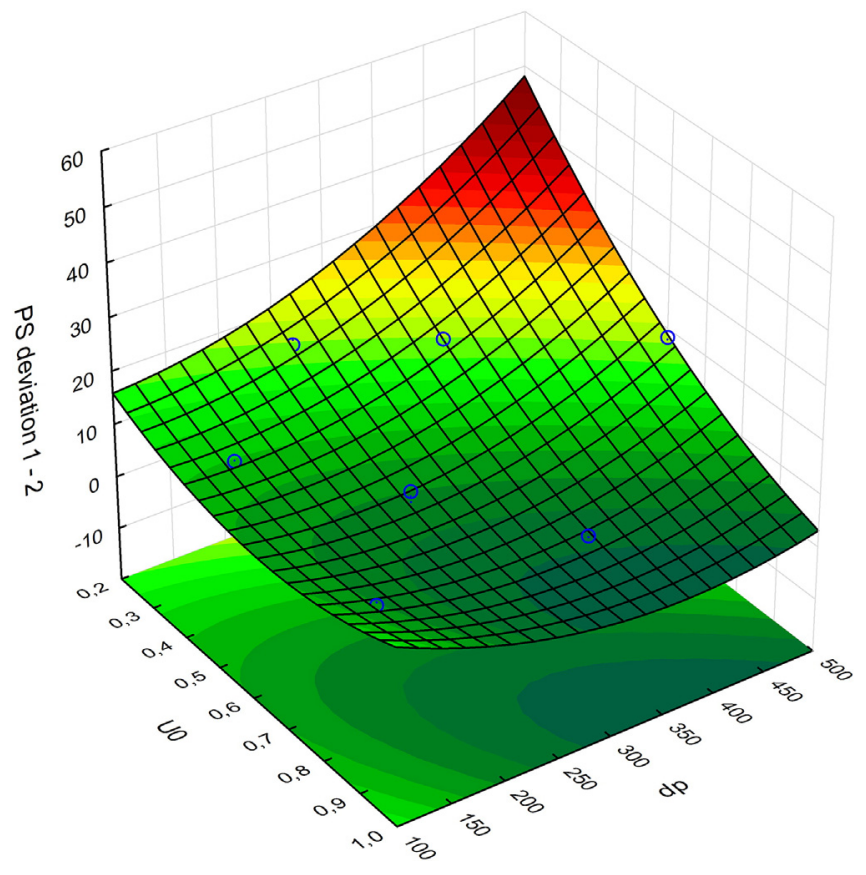

Fig. 3. Response of the percentage deviation of the phase segregation in CCD 1 (no frictional pressure) from that in CCD 2 (with frictional pressure) to changes in the fluidisation velocity (U0) and the particle size (dp).

difference in the emulsion phase volume fraction becomes increasingly significant.

The RMS of the solids volume fraction is over-predicted when the frictional pressure is neglected for two primary reasons. Firstly, the maximum solids volume fraction is higher, implying that there now is a larger range over which the volume fraction can vary. Secondly, and arguably more importantly, the more compact emulsion phase is less permeable for the fluidising gas, implying that less gas rises through the emulsion phase and more gas rises through the bubble phase. This creates more bubbles and therefore more phase segregation. Fig. 4 is provided to illustrate these points.

Finally, when looking at the reactor performance, it is somewhat surprising that the mean difference between the two CCDs is so small $(-1.38 \%)$. It would be expected that the less permeable emulsion phase would cause significantly worse mass transfer and therefore worse reactor performance. The relatively large standard deviation (10.66\%) implies that this happens for some cases, but not for others. The response surfaces in Fig. 5 illustrate this variance.

It is clear that the expected negative deviation of CCD 1 from CCD 2 is observed over the majority of the parameter space, but a sharp positive deviation is observed for high fluidisation velocities, high bed heights and low particle sizes. This implies that, in these ranges, simulations without the inclusion of frictional pressure predict better reactor performance (higher degree of conversion) despite the much denser (and less penetrable) emulsion phase.

The reason for this phenomenon is best observed from animations of the solids volume fraction which can be observed in Figs. 12 to 15 in the following section. Essentially, the inclusion of the frictional pressure significantly increases the solids phase stresses, causing the bed to behave somewhat more solid-like. This causes larger bubbles to form at the reactor inlet and creates regular channelling of gas through the centre of the bed. Both of these phenomena reduce the quality of gas-solid contact and therefore decrease reactor performance. If the frictional pressure is not included, on the other hand, the bed behaves very liquid-like. Small bubbles are formed at the inlet and no channelling is observed.

These effects are especially visible at smaller particle sizes. As the particle size decreases, the emulsion phase becomes less penetrable to the fluidising gas and more gas is transported through the bubbles. 


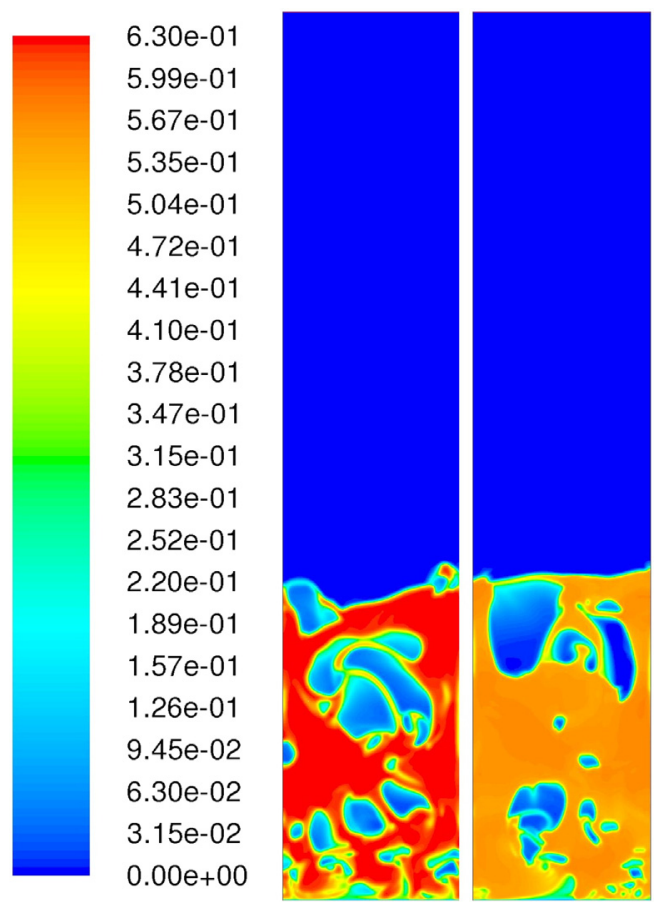

Fig. 4. Instantaneous solids volume fraction profiles for case 4 in Table 3 with (right) and without (left) the inclusion of fictional pressure.

This raises the likelihood of the channelling behaviour in the bed which substantially reduces reactor performance. When the bed height and fluidisation velocity are increased, these channels become longer and larger and therefore have a larger effect.

\subsubsection{Influence of the 3D geometry}

This section will isolate the effect of simulating the pseudo-2D reactor in 3D by comparing results from CCD 2 (2D) to CCD 3 (3D with no friction on the large front and back walls). The ANOVA of the deviation of CCD 2 from CCD 3 is given in Table 6.

Similar to the results in the previous section, a quick overview of the results can be gained by calculating the mean and standard deviation of the data set for each performance measure:

- Reactor performance: $-1.13 \pm 9.83$

- Bed expansion ratio: $4.92 \pm 4.34$

- Phase segregation: $8.47 \pm 5.56$.

On average, the 3D geometry does not seem to have a significant effect on the reactor performance, but there is a significant amount of variation in the difference between CCDs 2 and 3 across the parameter space. These effects will be further explored with the aid of the hydrodynamic performance measures (bed expansion ratio and phase segregation).

The bed expansion ratio is reduced by around $5 \%$ by simulating the bed in 3D. This is due to the inclusion of the extra degree of freedom which allows the gas to slip past the solids more efficiently. The standard deviation (4.34\%) indicates that there is also some variation in the difference between CCDs 2 and 3 across the parameter space and Table 6 shows that this variation is mostly due to the linear effect of particle size.

Fig. 6 shows this effect where it is seen that the bed expansions returned by the $2 \mathrm{D}$ and $3 \mathrm{D}$ simulations are very similar at large particle sizes, but the 2D simulation predicts increasingly higher bed expansions as the particle size is reduced. This is simply due to the smaller particle structures that are formed in beds with smaller particle sizes. As the bubbles and clusters reduce in size, more 3D effects become possible and the difference between 2D and 3D increases.

In addition, Fig. 6 appears to show a quadratic effect of fluidisation velocity even though Table 6 shows this effect to not be statistically significant. However, this effect can be understood by acknowledging that the 3D simulations can resolve smaller 3D bubbles at very low flowrates and also capture the smaller 3D structures that can occur under very vigorous fluidisation. Both these two extremes will decrease the amount of interphase slip in the 3D simulations and cause somewhat greater bed expansions. These effects are visible in the volume fraction contours given in Figs. 12 to 15.
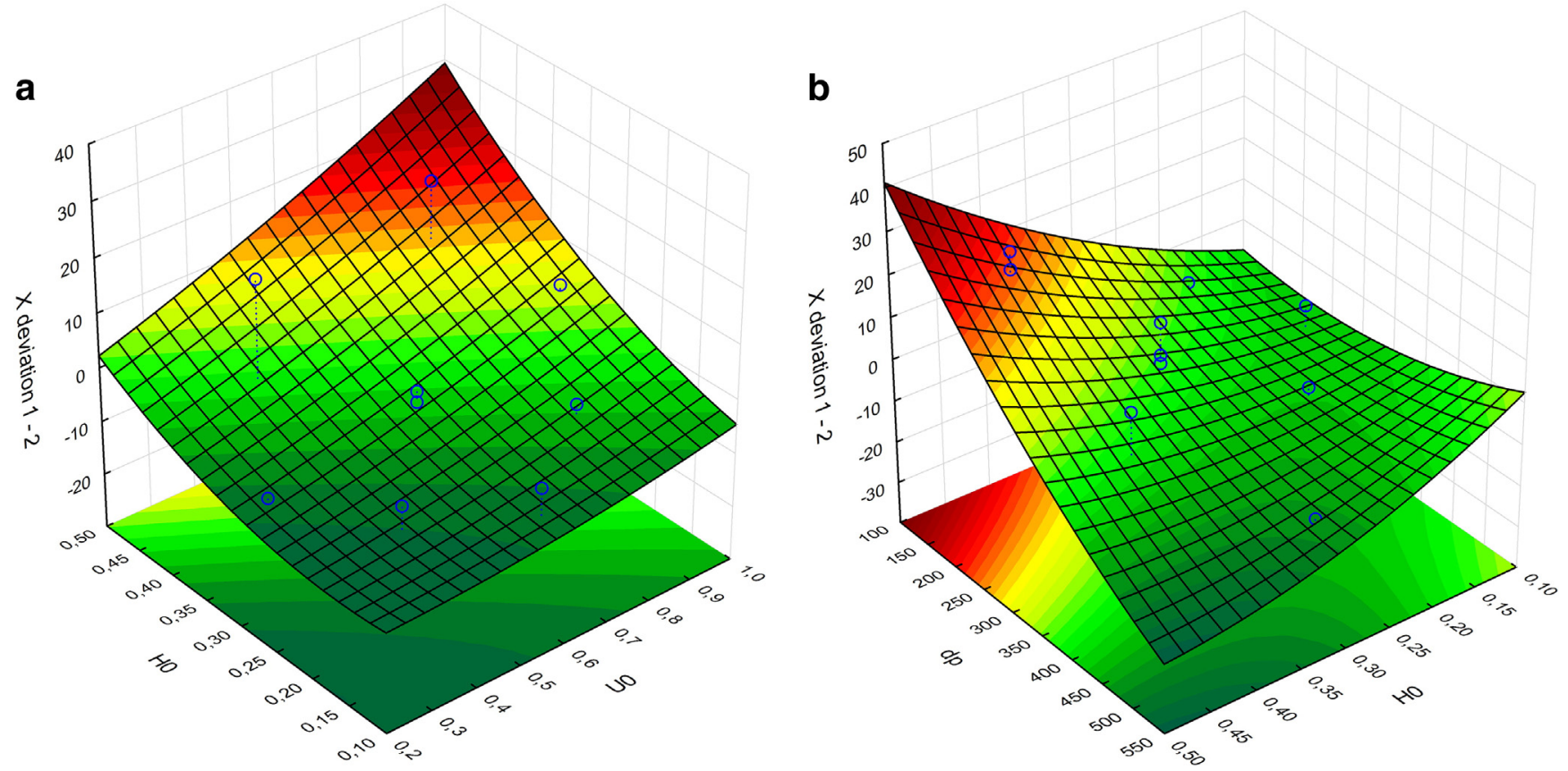

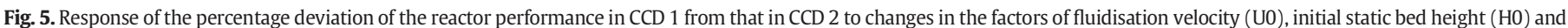
particle diameter (dp). 
Table 6

ANOVA table summarising the response of the deviations of CCD 2 from CCD 3 to changes in the three factors investigated. Significant factors are shown in bold, while highly significant factors are shown in bold italics. The factors are denoted by UO (fluidisation velocity), $\mathrm{HO}$ (static bed height), and dp (particle diameter). Different effects are indicated by L (linear), Q (quadratic) and by (interaction).

\begin{tabular}{|c|c|c|c|c|c|c|}
\hline \multirow[t]{2}{*}{ Effect } & \multicolumn{2}{|c|}{$\begin{array}{l}\text { Reactor } \\
\text { performance }\end{array}$} & \multicolumn{2}{|c|}{$\begin{array}{l}\text { Bed expansion } \\
\text { ratio }\end{array}$} & \multicolumn{2}{|c|}{ Phase segregation } \\
\hline & SS & p-Value & SS & p-Value & SS & p-Value \\
\hline U0 (L) & 28.88 & 0.0070 & 1.59 & 0.5130 & 41.47 & 0.0018 \\
\hline U0 (Q) & 3.87 & 0.1684 & 15.47 & 0.0798 & 0.02 & 0.8899 \\
\hline $\mathrm{HO}(\mathrm{L})$ & 13.00 & 0.0318 & 9.09 & 0.1535 & 12.71 & 0.0203 \\
\hline $\mathrm{HO}(\mathrm{Q})$ & 0.01 & 0.9555 & 1.34 & 0.5473 & 0.59 & 0.5019 \\
\hline $\mathrm{dp}(\mathrm{L})$ & 26.16 & 0.0086 & 53.61 & 0.0095 & 32.67 & 0.0030 \\
\hline $\mathrm{dp}(\mathrm{Q})$ & 4.32 & 0.1496 & 4.07 & 0.3120 & 0.07 & 0.8135 \\
\hline UO by $\mathrm{HO}$ & 0.12 & 0.7893 & 0.02 & 0.9438 & 1.14 & 0.3612 \\
\hline UO by dp & 2.81 & 0.2283 & 0.25 & 0.7912 & 2.29 & 0.2143 \\
\hline HO by dp & 12.59 & 0.0336 & 3.48 & 0.3459 & 3.37 & 0.1449 \\
\hline Error & 7.46 & & 16.09 & & 5.66 & \\
\hline Total & 100.00 & & 100.00 & & 100.00 & \\
\hline
\end{tabular}

When looking at the phase segregation, the 3D geometry causes an $8.47 \%$ decrease and also shows some variation within the parameter space (5.56\% standard deviation). Fig. 7 shows that the majority of the difference between the 2D and 3D simulations occurs at high fluidisation velocities and small particle sizes. It is under these circumstances that small 3D structures really start to play a significant role in the reactor behaviour. Further discussion on this point is postponed to the next section with the aid of Fig. 10.

Finally, the differences in reactor performance can be interpreted from this hydrodynamic analysis. The very small average difference between the reactor performances predicted by CCD 2 and CCD 3 $(-1.13 \%)$ is due to the effects of reduced bed expansion and decreased phase segregation cancelling each other out. Since the 3D bed is on average $4.92 \%$ shorter, but $8.47 \%$ less segregated, the gas has a shorter, but more efficient residence time in the reactor, eventually achieving a similar reactor performance. The variation of the difference in reactor performance over the parameter space is shown in Fig. 8 where it can be seen that the reactor performance is essentially a mirror image of the

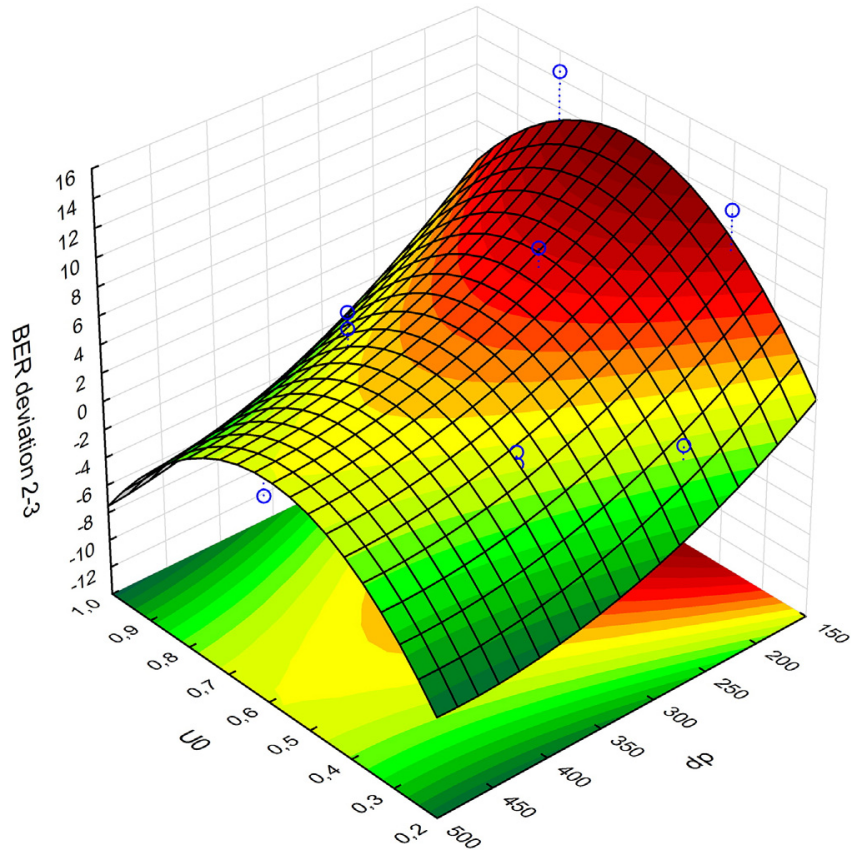

Fig. 6. Response of the percentage deviation of the bed expansion ratio in CCD 2 (2D) from that in CCD 3 (3D) to changes in the factors of fluidisation velocity (U0) and particle diameter $(d p)$.

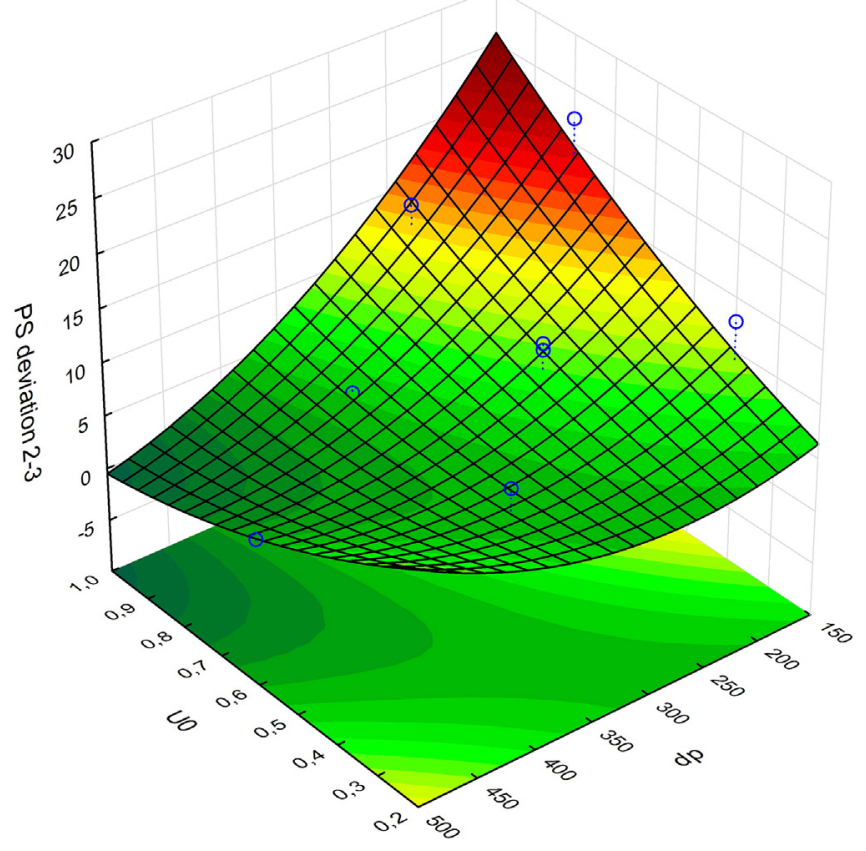

Fig. 7. Response of the percentage deviation of the phase segregation in CCD 2 (2D) from that in CCD 3 (3D) to changes in the factors of fluidisation velocity (U0) and particle diameter (dp).

phase segregation (Fig. 7). The reactor performance is predicted quite similarly for the majority of the parameter space, but at high fluidisation velocities and small particle sizes the $2 \mathrm{D}$ reactor performance is much poorer. This is simply the result of the much greater phase segregation predicted by the $2 \mathrm{D}$ simulations in this region.

\subsubsection{Influence of wall friction}

As shown in the preceding paper [6], the 2D simulations greatly over-predicted the solids velocities in the bed because the friction on the front and back walls was neglected. Results also indicated that this

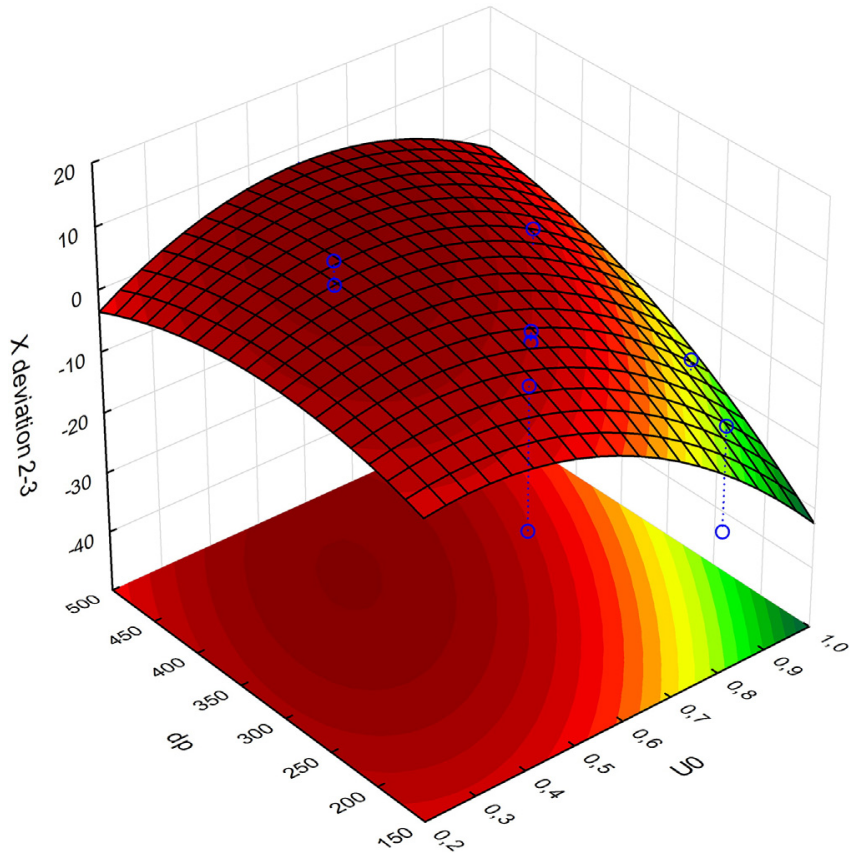

Fig. 8. Response of the percentage deviation of the reactor performance in CCD 2 (2D) from that in CCD 3 (3D) to changes in the factors of fluidisation velocity (UO) and particle diameter $(\mathrm{dp})$. 
Table 7

ANOVA table summarising the response of the deviations of CCD 3 from CCD 4 to changes in the three factors investigated. Significant factors are shown in bold, while highly significant factors are shown in bold italics. The factors are denoted by U0 (fluidisation velocity), HO (static bed height), and dp (particle diameter). Different effects are indicated by L (linear), Q (quadratic) and by (interaction).

\begin{tabular}{|c|c|c|c|c|c|c|}
\hline \multirow[t]{2}{*}{ Effect } & \multicolumn{2}{|c|}{$\begin{array}{l}\text { Reactor } \\
\text { performance }\end{array}$} & \multicolumn{2}{|c|}{$\begin{array}{l}\text { Bed expansion } \\
\text { ratio }\end{array}$} & \multicolumn{2}{|c|}{ Phase segregation } \\
\hline & SS & p-Value & SS & p-Value & SS & p-Value \\
\hline U0 (L) & 0.33 & 0.6672 & 0.06 & 0.8638 & 33.37 & 0.0016 \\
\hline U0 (Q) & 0.88 & 0.4877 & 2.84 & 0.2598 & 0.47 & 0.4940 \\
\hline $\mathrm{HO}(\mathrm{L})$ & 0.05 & 0.8696 & 1.69 & 0.3725 & 11.24 & 0.0154 \\
\hline $\mathrm{HO}(\mathrm{Q})$ & 11.20 & 0.0445 & 1.40 & 0.4139 & 0.46 & 0.4963 \\
\hline $\mathrm{dp}(\mathrm{L})$ & 47.59 & 0.0027 & 15.73 & 0.0305 & 12.07 & 0.0134 \\
\hline $\mathrm{dp}(\mathrm{Q})$ & 21.75 & 0.0137 & 20.10 & 0.0197 & 4.01 & 0.0837 \\
\hline UO by HO & 1.13 & 0.4359 & 0.28 & 0.7060 & 1.46 & 0.2499 \\
\hline UO by dp & 8.20 & 0.0713 & 45.72 & 0.0038 & 15.09 & 0.0086 \\
\hline HO by dp & 1.01 & 0.4593 & 3.38 & 0.2247 & 17.51 & 0.0064 \\
\hline Error & 7.87 & & 8.81 & & 4.32 & \\
\hline Total & 100.00 & & 100.00 & & 100.00 & \\
\hline
\end{tabular}

friction was the only reason for the large deviation. When the 3D case was run with perfectly smooth front and back walls, the 3D results matched the 2D results. However, this was done for the case with $500 \mu \mathrm{m}$ particles (case 14 in Table 3). As was shown in the preceding section, cases with smaller particles and larger fluidisation velocities showed a significant influence of the 3D domain even when no friction is included on the front and back walls.

This section will therefore isolate the effect of the friction on the front and back walls of the pseudo-2D bed by comparing 3D simulations without wall friction (CCD 3) to 3D simulations with wall friction (CCD 4). The ANOVA for the deviation of CCD 3 from CCD 4 is given in Table 7.

Once again, the mean and standard deviation of the data set will first be reported for each performance measure:

- Reactor performance: $-15.93 \pm 4.53$

- Bed expansion ratio: $1.42 \pm 3.96$

- Phase segregation: $10.83 \pm 10.86$.
The first noticeable figure is the $15.93 \%$ average increase in reactor performance caused by the friction at the front and back walls. This is simply due to the strong deceleration of the solids (the preceding paper [6] showed that the inclusion of wall friction reduced solids velocities by a factor of 4) and the greater amount of gas that is forced through the emulsion phase as a result. The variation in the difference between CCDs 3 and 4 (4.53\% standard deviation) is not very large and can be seen from Table 7 to be in response to changes in the particle size: the factor which has the greatest influence on emulsion phase permeability.

The effect of wall friction on the bed expansion ratio also seems to be quite small. This lack of a large effect is interesting because it implies that the large differences in solids velocity caused by the inclusion of wall friction do not affect the expanded bed height. It therefore appears that the 3D geometry itself has a significantly greater effect on the expanded bed height than the friction on the front and back walls.

The degree of phase segregation is strongly influenced by the inclusion of wall friction, however, and these effects will be discussed in more detail. Firstly, the large mean reduction in phase segregation caused by the inclusion of wall friction $(10.83 \%)$ is a result of the friction at the walls dragging more solids into the rising bubbles, thereby reducing the degree of phase segregation. Fig. 9 shows that this effect is more prevalent at high fluidisation velocities, low static bed heights and small particle sizes. For low fluidisation velocities and large particle sizes, this effect is small (the sharp negative deviation in this region in Fig. 9 is the result of an unphysical extrapolation of the model fit).

These effects can be interpreted with the aid of Fig. 10 where it is shown that the phase segregation profiles for the case with a low fluidisation velocity and large particle size behaved very similarly in CCDs 2, 3 and 4, while the case with high fluidisation velocity and small particle size behaved quite differently.

The right hand side of Fig. 10 clearly shows the influence of the 3D geometry and the presence of walls on the degree of phase segregation. The 3D geometry allows for smaller 3D structures to form inside the bubbles and this phenomenon becomes a lot stronger when strong wall shear is included. Naturally, this effect will increase with increased fluidisation velocity (more shearing) and decreased particle size (smaller 3D structures). When looking at the lower regions of the right hand
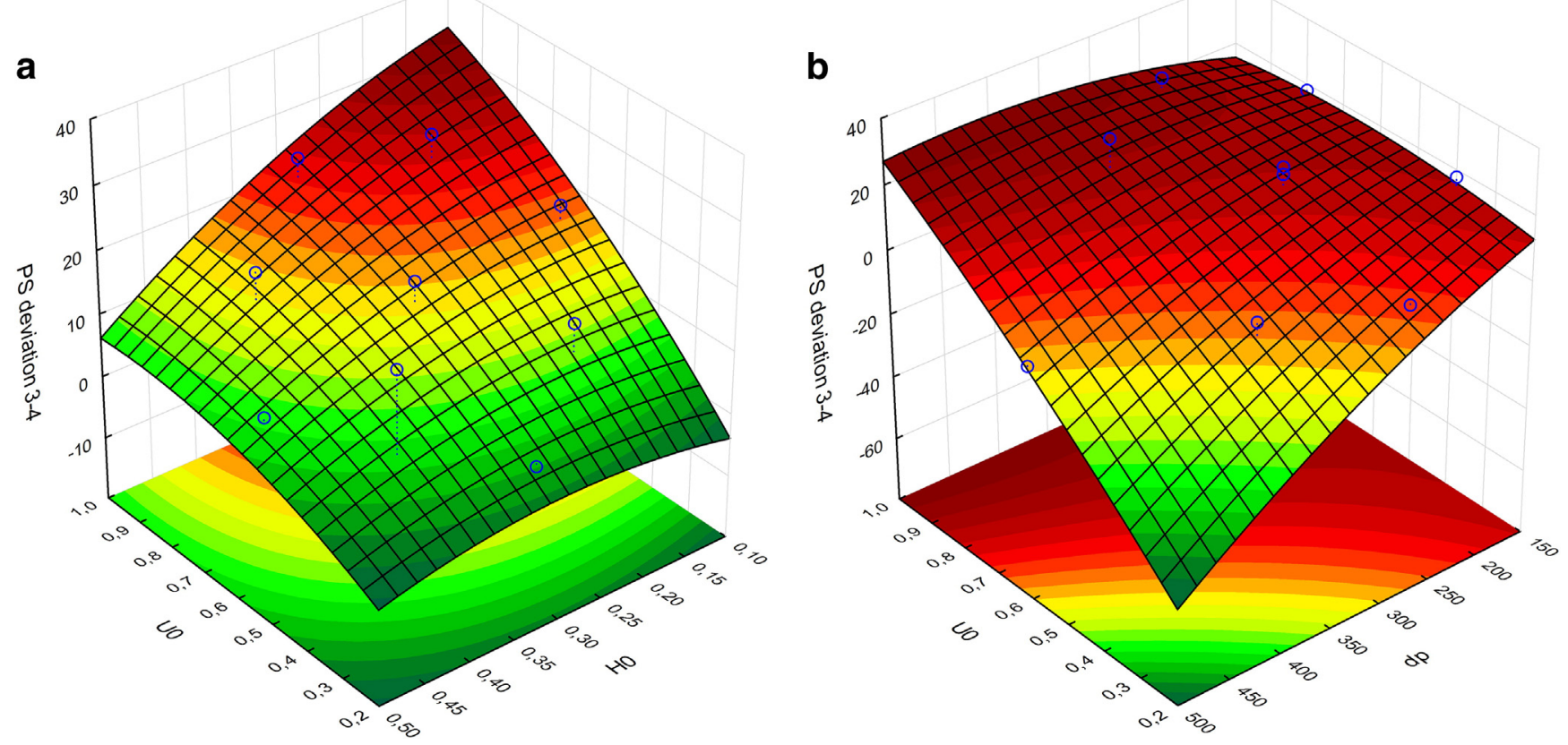

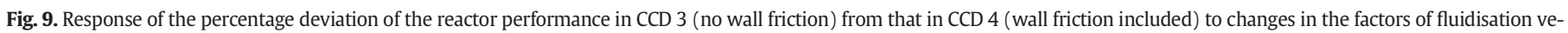
locity (U0), static bed height (HO) and particle diameter (dp). 

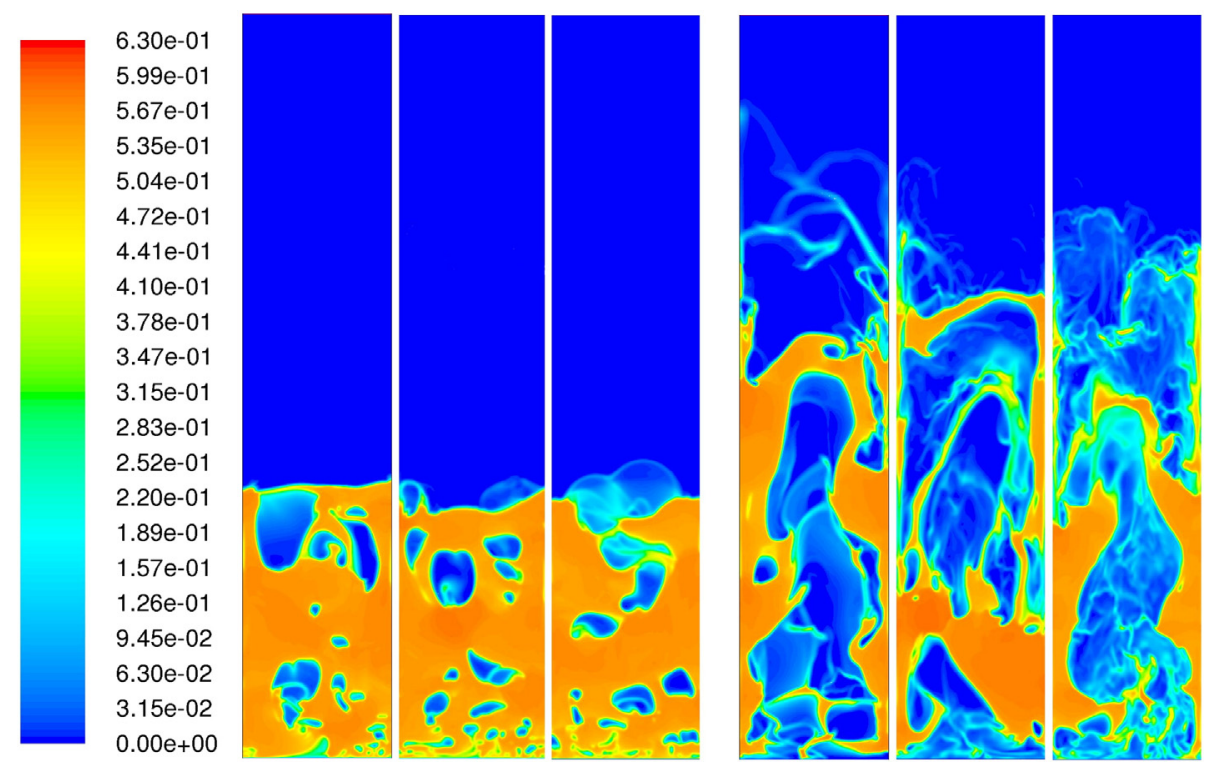

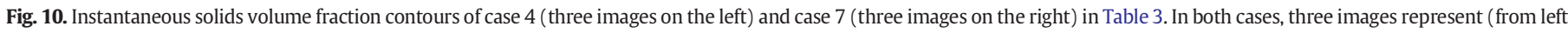
to right) CCD 2 (2D), CCD 3 (3D) and CCD 4 (3D with wall friction).

side of Fig. 10, it can also be seen that the region close to the inlet is especially susceptible to these phenomena, thereby increasing the relative magnitude of this effect in shorter beds.

One very interesting observation from these data is the fact that Table 7 shows a very large influence of fluidisation velocity on phase segregation, but no influence on reactor performance. It would be expected that the large decrease in phase segregation caused by the inclusion of wall friction would also cause a significant increase in reactor performance, but this increase is not observed.

The most likely explanation for this effect is the complementary nature of the two phenomena which increase reactor performance when wall friction is included: (1) the slowing down of solids, forcing more gas to pass through the emulsion phase and (2) the shear at the walls dragging more solids into the bubbles, causing better gas/solid contact. It is expected that the first effect is much stronger at low fluidisation velocities where a larger fraction of the gas passes through the emulsion, while the second effect (the one measured by the phase segregation performance measure) will be much stronger at higher fluidisation velocities.

It can therefore be reasoned that the large mean increase in reactor performance (15.93\%) with the inclusion of wall friction results from both these phenomena and that the relative strength of these phenomena tends to keep this increase constant as the fluidisation velocity is increased.

\subsubsection{Comparisons to experimental data}

Finally, the expanded bed height results from CCDs 1,2 and 4 will be compared to experimental measurements [6]. CCD 3 will be excluded for the sake of brevity because there was very little difference in the expanded bed heights returned by CCDs 3 and 4 . The same method of percentage deviation will be employed to quantify the percentage by which each simulation result deviates from its experimental counterpart. The ANOVA for these results is given in Table 8 .

The means and standard deviations for these three sets of data are as follows:

- CCD 1: $-1.68 \pm 10.67$

- CCD 2: $-0.11 \pm 10.44$

- CCD 4: $-5.93 \pm 10.03$.

Interestingly, there is not much difference between the comparisons of the three different CCDs to experiments. If anything, the 3D simulations seem to fare poorer, showing an average $6 \%$ deviation from simulation results. All three CCDs also show a significant amount of variance in the deviations from experimental results. Table 8 indicates that this variance occurs in response to changes in the static bed height and the particle size. Fig. 11 shows the nature of this variance.

The similarity between the three simulation cases is quite striking. This could also be seen from the relatively small difference observed between the predictions of the bed height in the previous sections. All three CCDs appear to not correctly capture the effect of the static bed height, but the effect of the particle size appears to be largely captured by the 3D simulations, at least for taller beds. It should also be mentioned that incomplete grid independence could lead to a small overprediction of bed expansion for smaller particles as touched upon in Section 2.4.

Table 8 and Fig. 11 show that the 2D simulations over-predict the effect the particle size on the bed expansion ratio. The improvement brought by the 3D simulations can be attributed to the correct predictions of central channelling of gas through the bed. The rapid slippage of gas through the bed which is caused by this channelling serves to decrease the bed expansion achieved by smaller particles. Therefore, if this

Table 8

ANOVA table summarising the response of the deviations of the three sets of simulations from experimental data to changes in the three factors investigated. Significant factors are shown in bold, while highly significant factors are shown in bold italics. The factors are denoted by U0 (fluidisation velocity), HO (static bed height), and dp (particle diameter). Different effects are indicated by $\mathrm{L}$ (linear), $\mathrm{Q}$ (quadratic) and by (interaction).

\begin{tabular}{|c|c|c|c|c|c|c|}
\hline \multirow[t]{2}{*}{ Effect } & \multicolumn{2}{|c|}{$\begin{array}{l}\text { CCD } 1 \text { - } \\
\text { experiments }\end{array}$} & \multicolumn{2}{|c|}{$\begin{array}{l}\text { CCD } 2 \text { - } \\
\text { experiments }\end{array}$} & \multicolumn{2}{|c|}{$\begin{array}{l}\text { CCD } 4- \\
\text { experiments }\end{array}$} \\
\hline & SS & p-Value & SS & p-Value & SS & p-Value \\
\hline U0 (L) & 0.04 & 0.8657 & 0.69 & 0.4490 & 1.06 & 0.3419 \\
\hline U0 (Q) & 1.92 & 0.2614 & 3.98 & 0.1062 & 0.09 & 0.7712 \\
\hline $\mathrm{HO}(\mathrm{L})$ & 48.37 & 0.0014 & 49.50 & 0.0010 & 70.86 & 0.0004 \\
\hline $\mathrm{HO}(\mathrm{Q})$ & 2.87 & 0.1823 & 5.57 & 0.0673 & 1.55 & 0.2591 \\
\hline $\mathrm{dp}(\mathrm{L})$ & 33.96 & 0.0031 & 27.16 & 0.0036 & 14.87 & 0.0110 \\
\hline $\mathrm{dp}(\mathrm{Q})$ & 2.82 & 0.1854 & 0.14 & 0.7300 & 1.78 & 0.2318 \\
\hline UO by HO & 3.53 & 0.1466 & 4.46 & 0.0916 & 2.65 & 0.1573 \\
\hline UO by dp & 0.38 & 0.5956 & 2.18 & 0.2048 & 1.21 & 0.3128 \\
\hline HO by dp & 0.15 & 0.7389 & 1.18 & 0.3320 & 1.13 & 0.3278 \\
\hline Error & 5.98 & & 5.14 & & 4.80 & \\
\hline Total & 100.00 & & 100.00 & & 100.00 & \\
\hline
\end{tabular}



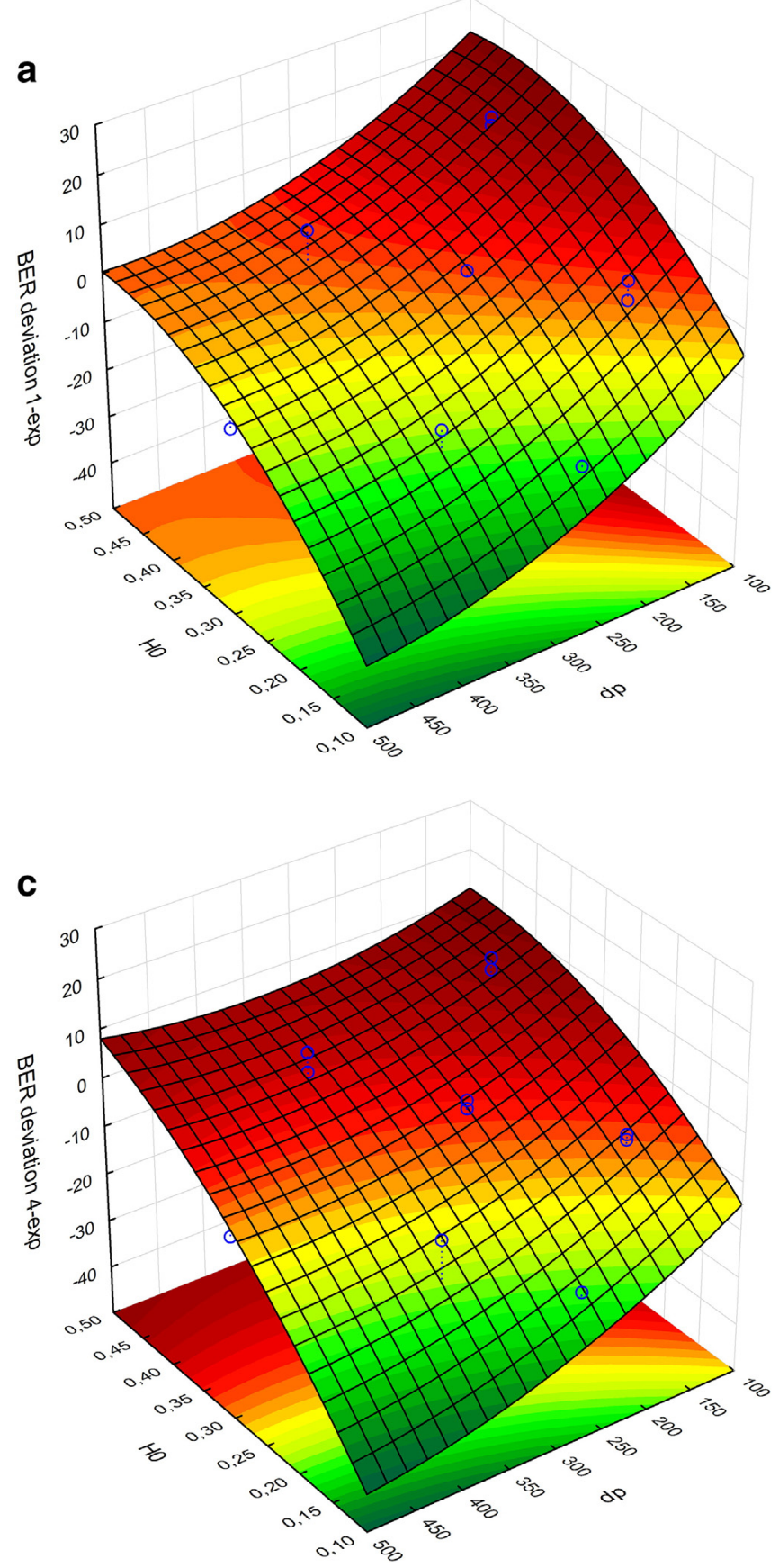

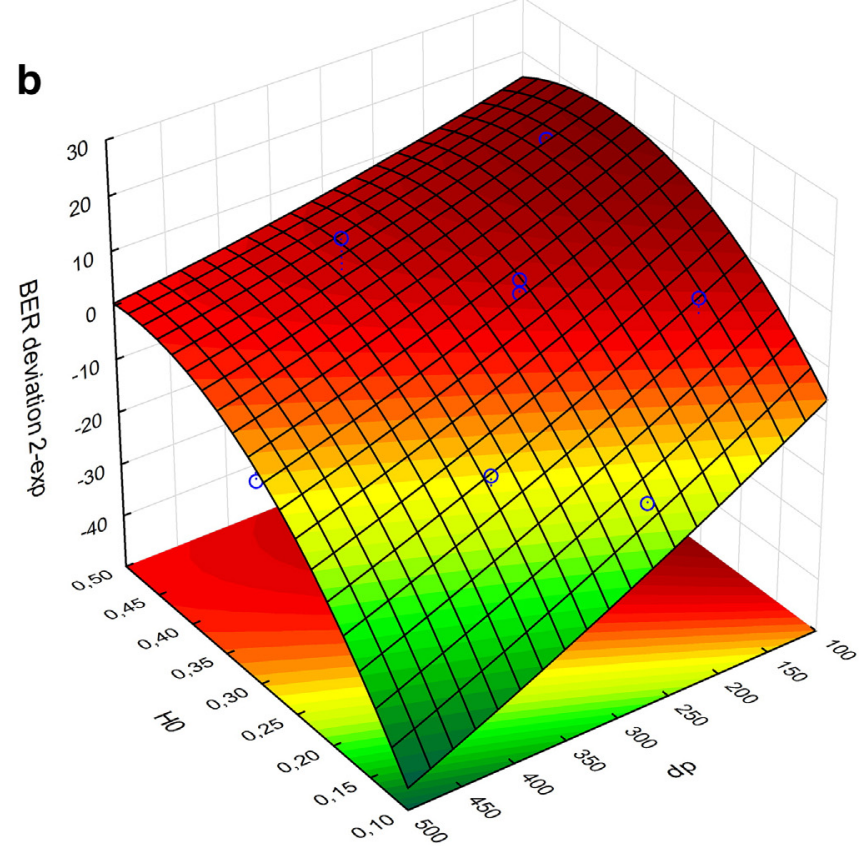

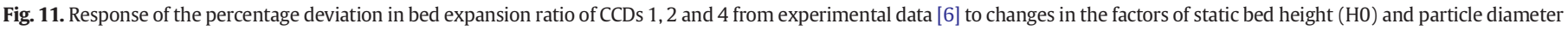
(dp).

channelling is not correctly captured, the bed expansion will be overpredicted.

It is clear, however, that the full 3D simulations did not manage to correct the relatively large error in the simulation response to changes in the static bed height. As shown in Table 4, the simulations predict the bed expansion ratio to be relatively independent of the static bed height. The experiments, however, showed the effect of the static bed height to be much larger than the effect of the particle size [6].

Experimental bed expansion ratios increased for smaller static bed heights because the bubbles forming close to the distributor plate are much smaller and should therefore rise slower and cause more bed expansion. If the bed is tall, on the other hand, the bubbles have the opportunity to grow and increase their velocity, thereby gradually reducing the bed expansion ratio. This effect seems to not be captured by the simulations. An initial investigation into various other model parameters which could improve model behaviour is presented in Section 4.3.

\subsection{Qualitative visual comparisons}

Studying animations of the simulations and experiments gives some valuable additional information on simulation accuracy. In general, animations showed that CCD 1 behaved far too free-flowing and liquid-like and did not provide reasonable comparisons to experiments. CCD 2 produced animations that behaved somewhat more solid-like in most cases, but in some cases it was hard to distinguish between CCDs 1 and 2. CCD 3 showed some more realistic 3D effects at smaller particle sizes, but still behaved too liquid-like and free flowing. It was only 


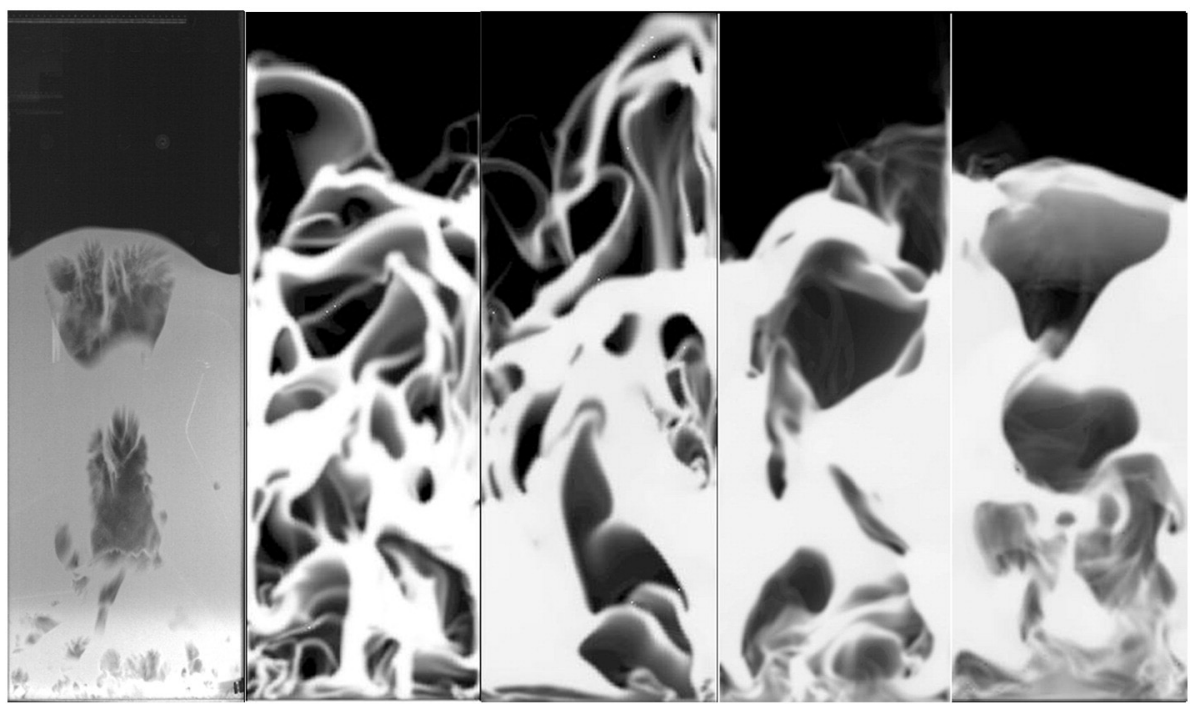

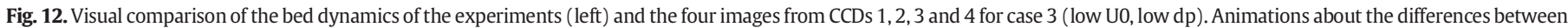
simulations (Case_03.mpg) and the comparison to experiments (Experimental_comparison.mpg) are included in the submission.

when the effect of the front and back walls was included in CCD 4 that a very satisfactory match in bed dynamics across all cases was attained.

Indeed, animations from CCD 4 are strikingly similar to animations from experiments and provide good confidence in the model performance. The correct prediction of channelling behaviour at high flow rates and smaller particle sizes was especially encouraging. As an illustration, animations comparing CCDs 1, 2, 3 and 4 as well as animations comparing CCD 4 to experiments are attached as supplementary material to this submission for cases 3, 4, 7 and 8 in Table 3. For the experimental comparison, the grey levels and brightness of the simulations were adjusted as discussed around Fig. 16.

For discussion in this paper, however, snapshots of solids volume fraction contours will be provided for comparison against images from the experiments. In order to compare more realistically to experiments, solids volume fraction plots of the 3D simulations were assembled from three cut planes through the domain: one on the front wall, one in the centre and one on the back wall. The transparency of the plane on the front wall was set to $75 \%$ and the transparency of the plane in the centre was set to $50 \%$. In this way, the front view of the three planes showed the average volume fraction on all three planes.

Since the different modelling methodologies differed most when predicting changes to the fluidisation velocity and the particle size, snapshots will be given of cases 3 (Fig. 12), 4 (Fig. 13), 7 (Fig. 14) and 8 (Fig. 15). Respectively, the levels of the fluidisation rate and the particle size for these four cases are low-low, low-high, high-low and high-high.

When comparing the experimental and simulation images, it is important to note that the simulation images appear to contain more bubble volume than the experimental images. This is because the simulation images see a clean bubble (solids volume fraction of 0 ) as black and maximum packing (solids volume fraction at 0.63 ) as white with everything in between falling somewhere on the grey scale. For the experiments, however, even particle volume fractions of 0.3 might already completely obscure the dark back plate of the pseudo-2D reactor, creating the impression of an emulsion phase at maximum packing. This effect can be corrected for by adjusting the grey levels and brightness of the simulation images to get a

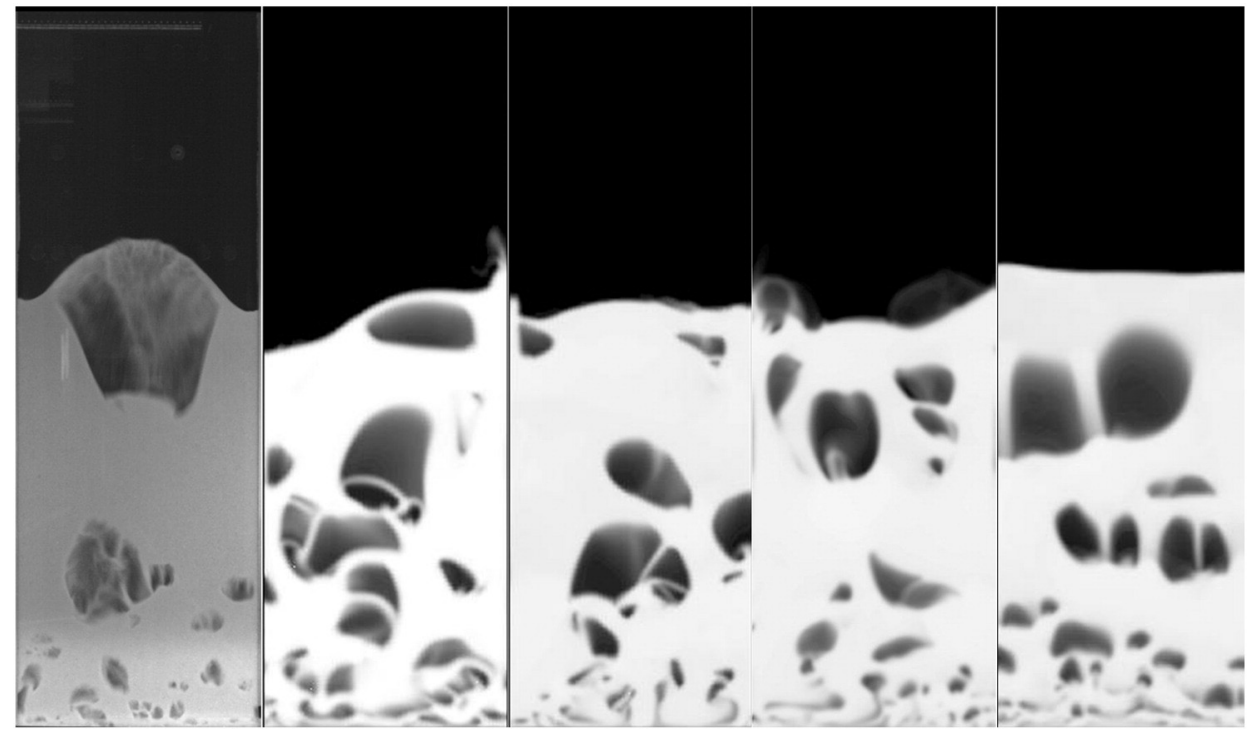

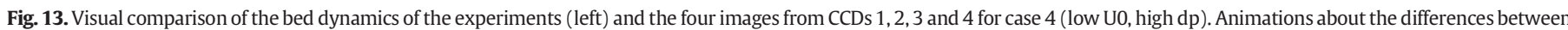
simulations (Case_04.mpg) and the comparison to experiments (Experimental_comparison.mpg) are included in the submission. 


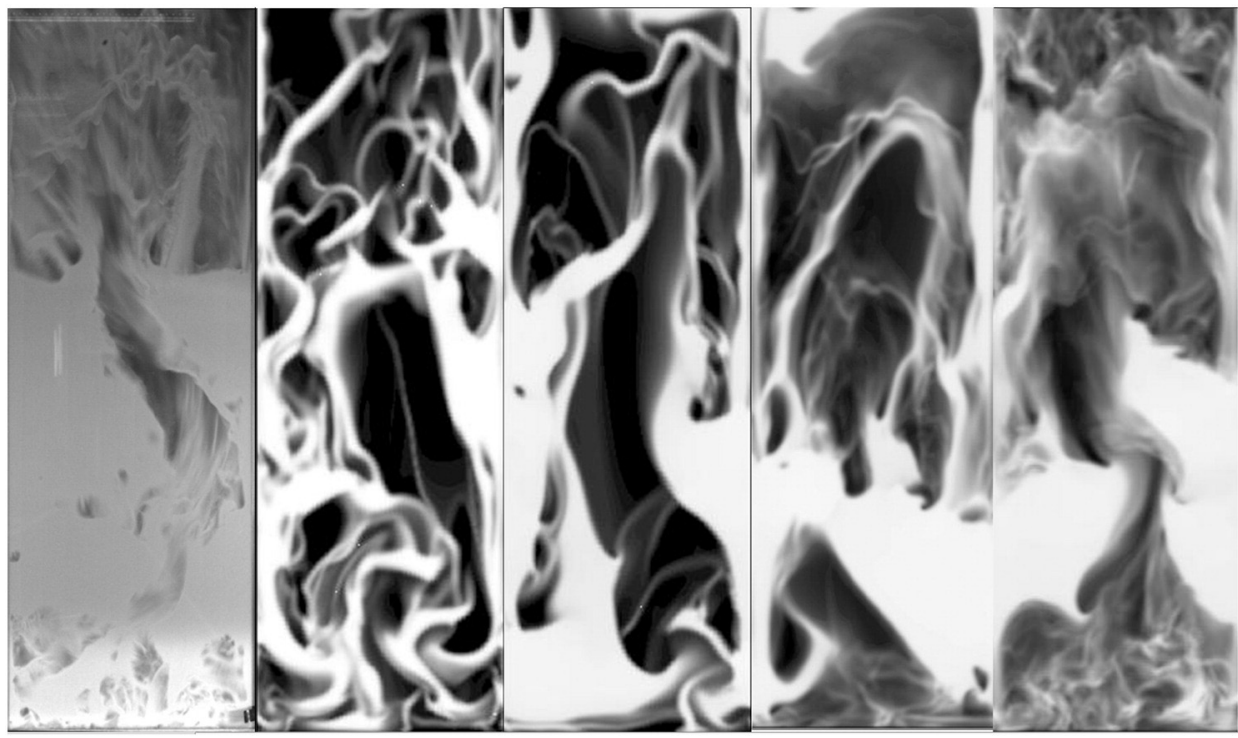

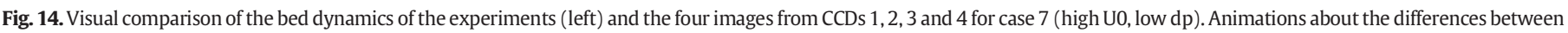
simulations (Case_07.mpg) and the comparison to experiments (Experimental_comparison.mpg) are included in the submission.

better comparison. For example, the adjusted comparison between the experiment and the 3D simulation with wall friction for case 7 (Fig. 14) is shown in Fig. 16.

Still, these figures clearly show that the 3D simulations give the best representation of the bubble dynamics. It is also clear that the bubble dynamics from the four CCDs become more similar for smaller fluidisation velocities and larger particle sizes and show large differences for higher fluidisation velocities and smaller particle sizes. In these cases, the solids velocity decreases and the wall effects become less important.

From animations, however, it is still clear that the solids velocities even in these cases are still significantly greater in the 2D beds than in the 3D bed. Fig. 17 shows that the solids velocities from CCDs 1, 2 and 3 are virtually identical, but the solids velocity for CCD 4 is a lot smaller. As discussed in [6], this significant reduction in solids velocity matches with experimental measurements.

\subsection{Evaluation of other parameters}

As shown in Fig. 11, the model deviates most significantly from experimental observations in cases with low static bed heights. For this reason, the influence of various other model settings will be evaluated based on case 11 in Table 2 (the case with the lowest static bed height). The following model settings will be evaluated:

- The classic drag model of Wen and Yu [23] (Eqs. (28)-(30)). This model has been shown to predict slightly higher bed expansions than the model of Syamlal and O'Brien used in this work $[10,11]$.

- Higher particle-particle restitution coefficients than the value of 0.9 used in this study. Values of 0.95 and 0.99 will be evaluated in line with the findings of $[11,14]$.

- A visco-plastic frictional stress formulation as derived by Jop et al. [24] (Eqs. (31)-(33)).

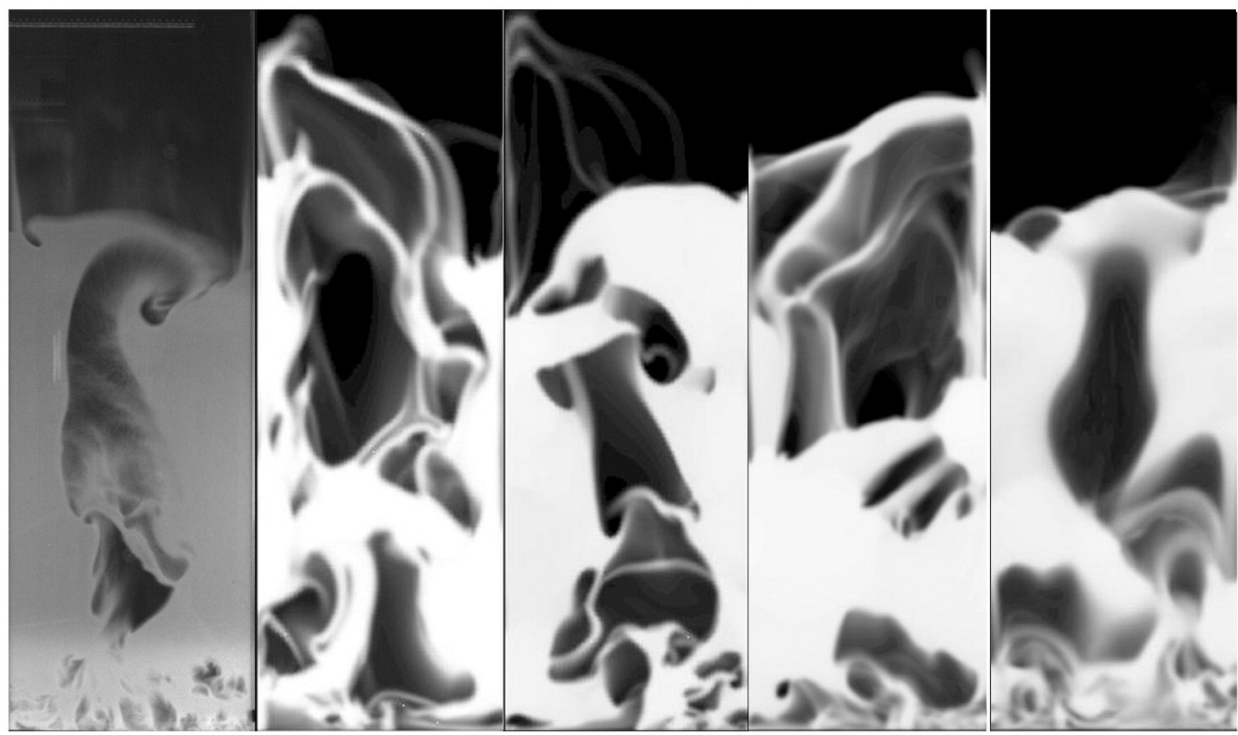

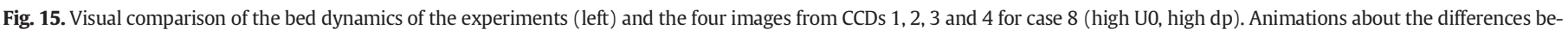
tween simulations (Case_08.mpg) and the comparison to experiments (Experimental_comparison.mpg) are included in the submission. 


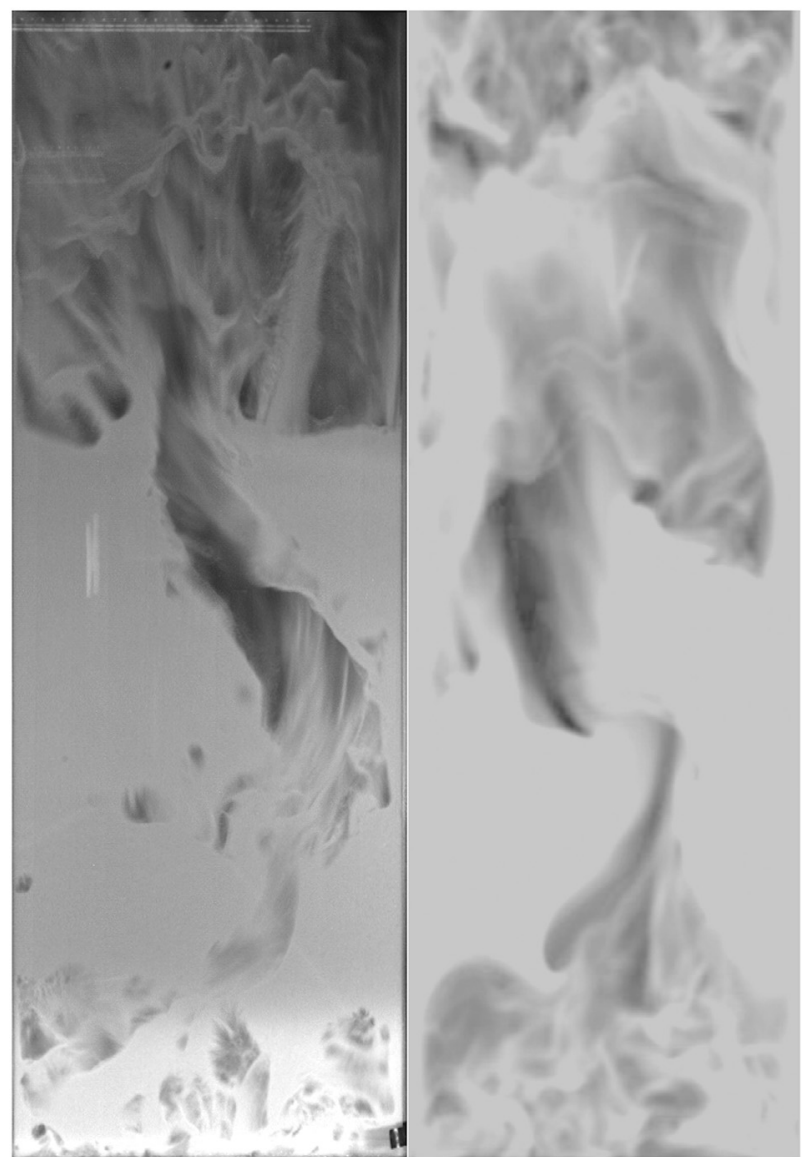

Fig. 16. Visual comparison of the bed dynamics for the experiment (left) and the 3D simulation with adjusted grey levels and brightness (right) for case 7 . The same images were used as in Fig. 14. The animation comparing the experiments (Experimental_comparison.mpg) was made in this manner.

- An alternative radial distribution function from the work of Iddir and Arastoopour [25] (Eq. (34)).

- The solution of the full partial differential equation (Eq. (14)) for the conservation of granular temperature. Here the granular temperature diffusion coefficient was modelled according to [3] (Eq. (35)).

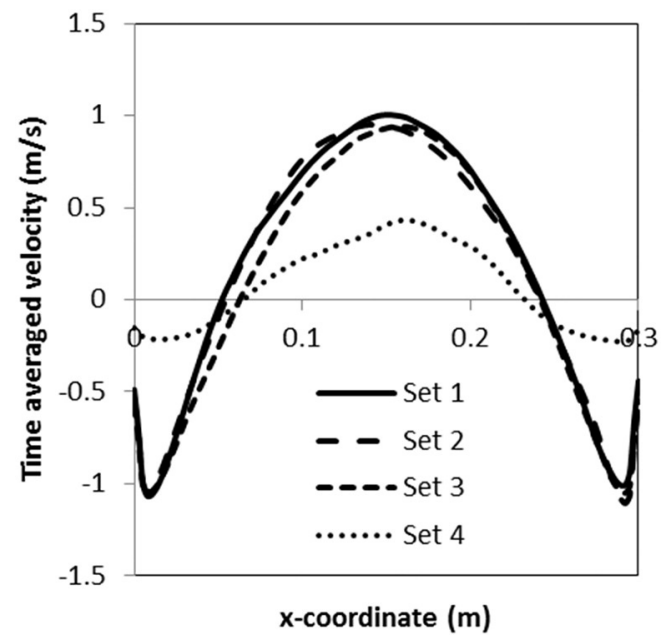

Fig. 17. Cross-stream time averaged vertical solids velocity at a height of $0.3 \mathrm{~m}$ for case 15 in all four CCDs.
- Inclusion of full modelling of the plenum and distributor with a compressible gas so as to allow for spatial and temporal flow variations across the distributor.

- Using second order discretisation in time.

$K_{g s}=\frac{3}{4} C_{D} \frac{\alpha_{s} \alpha_{g} \rho_{g}\left|\vec{v}_{s}-\vec{v}_{g}\right|}{d_{s}} \alpha_{g}^{-2.65}$

$C_{D}=\frac{24}{\alpha_{g} \operatorname{Re}_{S}}\left(1+0.15\left(\alpha_{g} \operatorname{Re}_{s}\right)^{0.687}\right)$

$\operatorname{Re}_{s}=\frac{\rho_{g} d_{s}\left|\vec{v}_{s}-\vec{v}_{g}\right|}{\mu_{g}}$

$\mu_{s, f r i c}=\frac{v_{f} p_{s}}{\sqrt{I_{2 D}}}$

$v_{f}=\tan \left(20.9^{\circ}\right)+\frac{\left(\tan \left(32.76^{\circ}\right)-\tan \left(20.9^{\circ}\right)\right)}{\left(\frac{0.279}{I}+1\right)}$

$I=\frac{d_{s} \sqrt{I_{2 D}}}{\sqrt{p_{s} / \rho_{s}}}$

$g_{0, s s}=\left(1-\frac{\alpha_{s}}{\alpha_{s, \max }}\right)^{-1}$

$k_{\theta_{s}}=\frac{15 d_{s} \rho_{s} \alpha_{s} \sqrt{\Theta_{s} \pi}}{4(41-33 \eta)}\left[1+\frac{12}{5} \eta^{2}(4 \eta-3) \alpha_{s} g_{0, s s}+\frac{16}{15 \pi}(41-33 \eta) \eta \alpha_{s} g_{0, s s}\right]$

$\eta=\frac{1}{2}\left(1+e_{s s}\right)$

Results of these eight new cases are presented in Table 9 in comparison with the simulation setup used in the previous sections (base case).

It is clear that the higher restitution coefficients resulted in the most substantial differences from the base case results. The case with a restitution coefficient of 0.99 resulted in a bed expansion ratio which got closest to the experimental value of 2.48 . A $16 \%$ decrease in reactor performance was also achieved by the alternative radial distribution function mainly as a result of a $7 \%$ increase in the amount of phase segregation resolved. Similarly, the alternative frictional stress model resulted in a $12 \%$ increase in phase segregation, leading to a $10 \%$ decrease in reactor performance.

Table 9

Results from the parametric study carried out on case 11 in Table 2. Deviations of more than $10 \%$ from the base case are highlighted using bold italics.

\begin{tabular}{llll}
\hline & $\begin{array}{l}\text { Reactor } \\
\text { performance }\end{array}$ & $\begin{array}{l}\text { Bed } \\
\text { expansion } \\
\text { ratio }\end{array}$ & $\begin{array}{l}\text { Phase } \\
\text { segregation }\end{array}$ \\
\hline Base case & 2.04 & 1.90 & 0.61 \\
Wen \& Yu drag & 1.90 & 1.89 & 0.61 \\
Restitution coefficient 0.95 & $\mathbf{2 . 4 1}$ & 1.94 & $\mathbf{0 . 5 4}$ \\
Restitution coefficient 0.99 & $\mathbf{3 . 3 1}$ & $\mathbf{2 . 1 6}$ & $\mathbf{0 . 4 1}$ \\
Jop et al. frictional stress & 1.85 & 1.93 & $\mathbf{0 . 6 8}$ \\
Iddir \& Arastoopour radial distribution & $\mathbf{1 . 7 2}$ & 1.86 & 0.66 \\
$\quad$ function & 1.96 & 1.83 & 0.60 \\
Full partial differential equation for & & & \\
$\quad$ granular temperature & 1.98 & 1.87 & 0.58 \\
$\quad$ Inclusion of the plenum and distributor & 1.96 & 1.89 & 0.63 \\
Second order time discretisation & & & \\
&
\end{tabular}


Snapshots of the solids distribution of all nine cases in Table 9 are shown in Fig. 18 in comparison with the experiment. It is clear that all cases significantly under-predict the bed expansion and that the cases with higher restitution coefficients are the only ones showing clear qualitative differences from the base case. Despite being closer to the correct bed expansion, the case with a restitution coefficient of 0.99 appears to not capture the bubble formation correctly.

Fig. 18 gives the impression that there are significantly more solids in the experimental case than in the simulated case, but this possibility has been eliminated via a repeated experiment which confirmed that the bed loading was correct. It therefore appears as if the emulsion phase in the experiments has a lower solids volume fraction than is the case in the simulations. Further work is required to understand and correct this clear simulation inaccuracy at low static bed heights. Experiments capable of more accurately measuring the solids volume fraction in the emulsion phase (e.g. optical probe) should be able to provide valuable insight into this matter.

\section{Conclusions}

A detailed simulation campaign has been conducted to understand the influences of the frictional pressure, the simulation geometry (2D/ 3D) and wall friction on the hydrodynamics and reactive performance of a pseudo-2D fluidised bed reactor. Simulations were carried out over a wide range of fluidisation velocities, bed loadings and particle sizes and it was found that the influences of the three aforementioned factors varied significantly through this parameter space.

Inclusion of the friction pressure had two primary effects: 1) the emulsion phase was solved to be at a solids volume fraction of about $10 \%$ below maximum packing limit and 2) solids stresses increased significantly. The reduced emulsion phase volume fraction generally improved reactor performance (degree of gas conversion achieved) by making the emulsion phase more penetrable to the gas. At high fluidisation velocities, high bed loadings and small particle sizes, on the other hand, the more solids-like behaviour caused by the increased solids stresses created some channelling behaviour which significantly increased gas slippage and reduced reactor performance.

Simulating the bed on a 3D geometry only had a significant effect at small particle sizes and high fluidisation velocities. Under these circumstances, small 3D particle clusters are formed in the 3D domain which cannot be captured by a 2D simulation. Resolution of these 3D structures caused a decrease in the bed expansion ratio (the gas now has an extra degree of freedom to slip past the solids), a decrease in the phase segregation (bubbles now contained more particles in the form of these 3D structures) and an increase in reactor performance (the presence of structures in the bubbles reduced the mass transfer resistance).

When the friction on the large front and back walls was included in the 3D simulations, the solids phase is slowed down significantly. This deceleration of the solids phase forced more gas through the emulsion phase and thereby caused a significant mean increase in reactor performance. At smaller particle sizes and high fluidisation velocities, the inclusion of wall friction also caused a strong increase in the amount of solids being entrained into the bubbles as small 3D structures. This significantly reduced the phase segregation, thereby improving mass transfer and increasing reactor performance.

Animations showed that the bubble dynamics resolved in the 3D simulations with frictional pressure and wall friction included matched qualitatively very well to the bubble dynamics observed in the experiments. The very accurate reproduction of channelling behaviour at higher gas flow rates was especially encouraging to observe and gives good confidence that the full model gives an accurate representation of reality.

Quantitatively, comparisons to experimental data showed that the bed expansion ratios returned by the full 3D simulations responded accurately to changes in the fluidisation velocity and particle size. However, an unexplained discrepancy still remained in response to the bed loading, causing a significant under-prediction of bed expansion at low bed loadings.

A range of model parameters were investigated in an attempt to correct the substantial under-prediction of bed expansion at low bed loadings, but the desired improvements could not be achieved. More
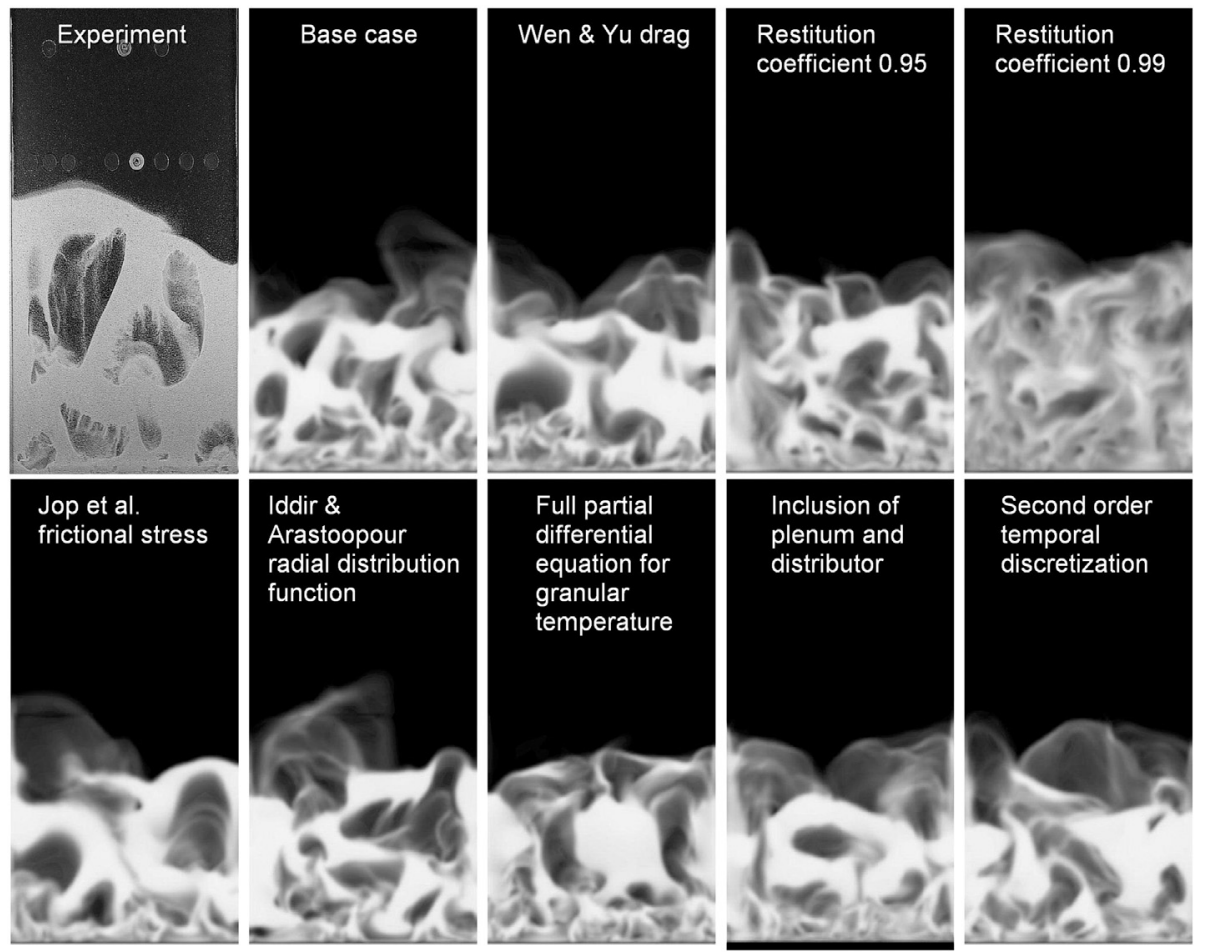
detailed investigations into this discrepancy will be performed in a future work.

\section{Acknowledgements}

The authors would like to express their gratitude for the financial support from the Research Council of Norway under the Flow@CLC grant (project number: 197580). In addition, this research was supported in part with computational resources at NTNU provided by NOTUR, http://www.notur.no.

\section{Appendix A. Supplementary data}

Supplementary data to this article can be found online at http://dx. doi.org/10.1016/j.powtec.2015.04.060.

\section{References}

[1] C.K.K. Lun, et al., Kinetic theories for granular flow: inelastic particles in Couette flow and slightly inelastic particles in a general flow field, J. Fluid Mech. 140 (1984) 223-256.

[2] D. Gidaspow, R. Bezburuah, J. Ding, Hydrodynamics of circulating fluidized beds, kinetic theory approach, 7th Engineering Foundation Conference on Fluidization 1992, pp. 75-82.

[3] M. Syamlal, W. Rogers, T.J. O'Brien, MFIX Documentation: Volume 1, Theory Guide, National Technical Information Service, Springfield, 1993.

[4] Y. Igci, S. Sundaresan, Constitutive models for filtered two-fluid models of fluidized gas-particle flows, Ind. Eng. Chem. Res. 50 (23) (2011) 13190-13201.

[5] S. Cloete, S.T. Johansen, S. Amini, An assessment of the ability of computational fluid dynamic models to predict reactive gas-solid flows in a fluidized bed, Powder Technol. 215-216 (2012) 15-25.

[6] S. Cloete, et al., The generality of the standard 2D TFM approach in predicting bubbling fluidized bed hydrodynamics, Powder Technol. 235 (2013) 735-746.

[7] K. Johansson, B.G.M. van Wachem, A.E. Almstedt, Experimental validation of CFD models for fluidized beds: influence of particle stress models, gas phase compressibility and air inflow models, Chem. Eng. Sci. 61 (5) (2006) 1705-1717.
[8] D.J. Patil, M. Van Sint Annaland, J.A.M. Kuipers, Critical comparison of hydrodynamic models for gas-solid fluidized beds - part II: freely bubbling gas-solid fluidized beds, Chem. Eng. Sci. 60 (1) (2005) 73-84.

[9] B.G.M. Van Wachem, et al., Comparative analysis of CFD models of dense gas-solid systems, AICHE J. 47 (5) (2001) 1035-1051

[10] F. Taghipour, N. Ellis, C. Wong, Experimental and computational study of gas-solid fluidized bed hydrodynamics, Chem. Eng. Sci. 60 (24) (2005) 6857-6867.

[11] Y. Wang, Z. Chao, H.A. Jakobsen, A sensitivity study of the two-fluid model closure parameters $(\beta, \mathrm{e})$ determining the main gas-solid flow pattern characteristics, Ind. Eng. Chem. Res. 49 (7) (2010) 3433-3441.

[12] F. Vejahati, et al., CFD simulation of gas-solid bubbling fluidized bed: a new method for adjusting drag law, Can. J. Chem. Eng. 87 (1) (2009) 19-30.

[13] E. Esmaili, N. Mahinpey, Adjustment of drag coefficient correlations in three dimensional CFD simulation of gas-solid bubbling fluidized bed, Adv. Eng. Softw. 42 (6) (2011) 375-386.

[14] C. Loha, H. Chattopadhyay, P.K. Chatterjee, Effect of coefficient of restitution in Euler-Euler CFD simulation of fluidized-bed hydrodynamics, Particuology 15 (2014) 170-177.

[15] S.H. Hosseini, et al., CFD simulation of the bubbling and slugging gas-solid fluidized beds, J. Fluids Eng. 132 (4) (2010) (041301-041301).

[16] D.G. Schaeffer, Instability in the evolution equations describing incompressible granular flow, J. Differ. Equ. 66 (1987) 19-50.

[17] S. Ogawa, A. Unemura, N. Oshima, On the equation of fully fluidized granular materials, J. Appl. Math. Phys. 31 (1980) 483.

[18] P.C. Johnson, R. Jackson, Frictional-collisional constitutive relations for granular materials, with application to plane shearing, J. Fluid Mech. 176 (1987) 67-93.

[19] S. Patankar, Numerical Heat Transfer and Fluid Flow, Hemisphere Publishing Corporation, United States, 1980.

[20] B.P. Leonard, S. Mokhtari, ULTRA-SHARP Nonoscillatory Convection Schemes for High-speed Steady Multidimensional Flow, NASA TM 1-2568 (ICOMP-90-12), NASA Lewis Research Center, 1990.

[21] D. Montgomery, Design and Analysis of Experiments, 5 ed. John Wiley and Sons, New York, 2001.

[22] S. Cloete, S.T. Johansen, S. Amini, Investigation into the effect of simulating a 3D cylindrical fluidized bed reactor on a 2D plane, Powder Technol. 239 (2013) 21-35.

[23] C.Y. Wen, Y.H. Yu, Mechanics of fluidization, Chem. Eng. Prog. Symp. Ser. 62 (1966) $100-111$.

[24] P. Jop, Y. Forterre, O. Pouliquen, A constitutive law for dense granular flows, Nature 441 (7094) (2006) 727-730.

[25] H. Iddir, H. Arastoopour, Modeling of multitype particle flow using the kinetic theory approach, AICHE J. 51 (6) (2005) 1620-1632. 